\title{
Binocular Spatial Phase Tuning Characteristics of Neurons in the Macaque Striate Cortex
}

\author{
EARL L. SMITH III, YUZO M. CHINO, JINREN NI, WILLIAM H. RIDDER III, AND M.L.J. CRAWFORD \\ College of Optometry, University of Houston, Houston, Texas 77204-6052
}

Smith, Earl L., III, Yuzo M. Chino, Jinren Ni, William H. Ridder III, and M.L.J. Crawford. Binocular spatial phase tuning characteristics of neurons in the macaque striate cortex. J. Neurophysiol. 78: 351-365, 1997. We employed microelectrode recording techniques to study the sensitivity of individual neurons in the striate cortex of anesthetized and paralyzed monkeys to relative interocular image disparities and to determine the effects of basic stimulus parameters on these cortical binocular interactions. The visual stimuli were drifting sine wave gratings. After the optimal stimulus orientation, spatial frequency, and direction of stimulus movement were found, the cells' disparity tuning characteristics were determined by measuring responses as a function of the relative interocular spatial phase of dichoptic grating pairs. No attempts were made to assess absolute position disparities or horizontal disparities relative to the horopter. The majority $(\sim 70 \%)$ of simple cells were highly sensitive to interocular spatial phase disparities, particularly neurons with balanced ocular dominances. Simple cells typically demonstrated binocular facilitation at the optimal phase disparity and binocular suppression for disparities $180^{\circ}$ away. Fewer complex cells were phase selective $(\sim 40 \%)$; however, the range of disparity selectivity in phase-sensitive complex cells was comparable with that for simple cells. Binocular interactions in non-phase-sensitive complex cells were evidenced by binocular response amplitudes that differed from responses to monocular stimulation. The degree of disparity tuning was independent of a cell's optimal orientation or the degree of direction tuning. However, disparity-sensitive cells tended to have narrow orientation tuning functions and the degree of disparity tuning was greatest for the optimal stimulus orientations. Rotating the stimulus for one eye $90^{\circ}$ from the optimal orientation usually eliminated binocular interactions. The effects of phase disparities on the binocular response amplitude were also greatest at the optimal spatial frequency. Thus a cell's sensitivity to absolute position disparities reflects its spatial tuning characteristics, with cells sensitive to high spatial frequencies being capable of signaling very small changes in image disparity. On the other hand, stimulus contrast had relatively little effect on a cell's disparity tuning, because response saturation occurred at the same contrast level for all relative interocular phase disparities. Thus, as with orientation tuning, a cell's optimal disparity and the degree of disparity selectivity were invariant with contrast. Overall, the results show that sensitivity to interocular spatial phase disparities is a common property of striate neurons. A cell's disparity tuning characteristics appear to largely reflect its monocular receptive field properties and the interocular balance between excitatory and inhibitory inputs. However, distinct functional classes of cortical neurons could not be discriminated on the basis of disparity sensitivity alone.

\section{INTRODUCTION}

In their early investigations of the primary visual cortex (V1 or striate cortex), Hubel and Wiesel $(1962,1968)$ discovered that the signals from the two eyes converge onto individual neurons so that the great majority of striate neu- rons can be excited by stimuli presented to either eye. Subsequently it was demonstrated in the cat (Barlow et al. 1967; Nikara et al. 1968) and then in the monkey (Hubel and Wiesel 1970; Poggio and Fischer 1977) that many of these binocular cortical neurons are very sensitive to interocular retinal image disparities. Thus the neural interactions required for two of the most fundamental properties of binocular vision, specifically fusion and stereopsis, are initiated at the first cortical center in the visual pathway.

More recent studies of binocular interactions in the primate visual cortex have concentrated primarily on either how individual neurons signal horizontal disparity information (Poggio 1984; Poggio and Fischer 1977; Poggio and Talbot 1981; Poggio et al. 1985, 1988) or exactly where in the visual cortex the neurophysiological analysis of stereoscopic information takes place (Burkhalter and Van Essen 1986; Felleman and Van Essen 1987; Maunsell and Van Essen 1983; Roy et al. 1992). Little information, however, is currently available on some of the more fundamental aspects of binocular interactions in the monkey cortex. For example, how are the inputs from the two eyes combined? In an elegant series of experiments, Ohzawa and Freeman (Freeman and Ohzawa 1990; Ohzawa and Freeman 1986a,b) used a dichoptic phase tuning paradigm (Freeman and Robson 1982 ) to determine the rules by which the inputs from the two eyes are combined in individual neurons in the cat visual cortex. The rules that govern binocular integration in the monkey's cortex have not been systematically studied even though this information is basic to any overall model of human binocular vision. These rules provide insight into cortical synaptic connectivity and how receptive fields in each eye are formed. Moreover, this information is important for understanding how binocular connections develop and the manner in which early abnormal visual experience influences cortical binocularity.

Although cortical neurons in the cat and monkey exhibit many common characteristics, there are important interspecies differences that preclude a direct extrapolation of data on cortical binocular integration from cats to primates. For example, comparisons of ocular dominance distributions show that fewer striate cortical neurons in the monkey exhibit equal or nearly equal inputs from the two eyes. The cortical ocular dominance columns show a higher degree of segregation in the monkey, particularly in the primary termination layers for afferents from the lateral geniculate nucleus. And in contrast to the cat, almost all of the cortical neurons in layer IVC of the monkey appear to be monocular (Hubel and Wiesel 1968). Therefore binocular integration in the monkey cortex may be delayed relative to that in the cat and possibly follow different rules of combination. 
The purpose of this investigation was to determine the sensitivity of neurons in the monkey striate cortex to the relative interocular spatial phase of dichoptically presented sine wave gratings. In particular, we wanted to determine how a number of basic stimulus parameters affect binocular phase tuning. In addition to providing important information on binocular integration, the results of this study provide the necessary foundation for our following studies on binocular contrast summation in individual neurons in the normal monkey cortex (Smith et al. 1997) and the residual binocular interactions in monkeys that experienced abnormal visual experience early in life (E. L. Smith III, J. Ni, H. Cheng, M.L.J. Crawford, R. S. Harwerth, and Y. M. Chino, unpublished data). Some of these results have been presented previously in abstract form (Ni et al. 1990; Smith et al. 1992a,b).

\section{METHODS}

\section{Subjects}

The subjects were 11 normal adult macaque monkeys (Macaca fascicularis, $n=9 ;$ M. mulatta, $n=2$ ). All experimental and animal care procedures were in compliance with the policies of the American Physiological Society.

\section{Surgical preparation and maintenance}

The monkeys were premedicated with atropine sulfate $(0.05 \mathrm{mg} /$ $\mathrm{kg} \mathrm{sc}$ ) and anesthetized initially with ketamine hydrochloride (15$20 \mathrm{mg} / \mathrm{kg} \mathrm{im})$ and acepromazine maleate $(0.15-0.2 \mathrm{mg} / \mathrm{kg})$. After venous cannulation, all subsequent surgical procedures were carried out under thiopental sodium anesthesia. A tracheotomy was performed to facilitate artificial respiration and the subject was secured in a stereotaxic instrument. An 8-mm craniotomy and durotomy were performed, exposing an area of striate cortex (V1) that represents the visual field at eccentricities between 1.5 and $4^{\circ}$. After all surgical procedures were completed, the animal was paralyzed with an intravenous infusion of pancuronium bromide (a loading dose of $0.1-0.2 \mathrm{mg} / \mathrm{kg}$ followed by a continuous infusion of $0.1-0.2 \mathrm{mg} \cdot \mathrm{kg}^{-1} \cdot \mathrm{h}^{-1}$ ) in a $5 \%$ dextrose Ringer solution $\left(2.5 \mathrm{mg} \cdot \mathrm{kg}^{-1} \cdot \mathrm{h}^{-1}\right)$ and artificially respired with a mixture of $59 \%$ $\mathrm{N}_{2} \mathrm{O}-39 \% \mathrm{O}_{2}-2 \% \mathrm{CO}_{2}$. The respiration parameters were adjusted to maintain the end-tidal $\mathrm{CO}_{2}$ between 4.0 and $4.5 \%$. Anesthesia was maintained by the continuous intravenous infusion of pentobarbital sodium $\left(2-4 \mathrm{mg} \cdot \mathrm{kg}^{-1} \cdot \mathrm{h}^{-1}\right)$. During the experiments, the anesthesia level was assessed by monitoring the electroencephalogram, electrocardiogram, and heart rate, particularly in response to a periodic finger pinch. Core temperature was measured with a rectal thermometer and was maintained at $37^{\circ} \mathrm{C}$.

Cycloplegia and mydriasis were produced with topically applied $1 \%$ atropine sulfate. Retinoscopy was used to determine the contact lens parameters required to focus the eyes for the stimulus screens. The accuracy of the refractive correction was fine tuned by examining the effects of additional trial lenses on the responses of individual neurons. At 12-h intervals, the contact lenses were removed and cleaned and a topical antibiotic and corticosteroid solution was instilled into the animal's eyes to reduce the potential for infection and inflammation. A monocular indirect ophthalmoscope that was fitted with a path-reversing mirror was used to identify the projections of the fovea and optic disk for each eye.

\section{Microelectrode recording procedures}

Epoxy-insulated tungsten microelectrodes $(10-20 \mathrm{M} \Omega$ at $1 \mathrm{kHz}$ ) were inserted into the operculum of the striate cortex at an oblique angle $\left(\sim 60^{\circ}\right)$. The electrical activity was conventionally amplified and the action potential waveforms were monitored on a storage oscilloscope. Conditioned pulses, which were provided by a window discriminator, were broadcast over an audio monitor and input to the computer.

At the end of a given electrode penetration, electrolytic lesions (5-10 $\mu \mathrm{A}, 5-10 \mathrm{~s}$, tip negative) were made at selected locations to aid in the identification of recording sites. At the end of the recording experiment, pentobarbital sodium $(100 \mathrm{mg} / \mathrm{kg})$ was administered intravenously to induce a deep level of anesthesia and the animals were killed by perfusion through the heart with Ringer solution followed by an aldehyde fixative (2\% paraformaldehyde and $0.5 \%$ glutaraldehyde in $0.1 \mathrm{M}$ phosphate buffer, $\mathrm{pH} 7.4$ ). The brains were removed and visual cortices were dehydrated through a sucrose series. Frozen sections $(40 \mu \mathrm{m})$ were cut tangential to the surface of the operculum and stained for cytochrome oxidase (Wong-Riley 1979). Composite drawings made from serial sections were used to locate the electrode tracks and the electrolytic lesions.

\section{Visual stimuli}

For each isolated neuron, the minimum response field for each eye (Barlow et al. 1967) was mapped on the tangent screen with the use of hand-held stimuli. Two gimbaled mirrors were used to reflect the projections of the receptive fields onto the approximate centers of two matched cathode ray tube (CRT) displays that had a space-average luminance of $54 \mathrm{~cd} / \mathrm{m}^{2}$ (P31 phosphors). Translucent plastic masks that had approximately the same luminance and color as the CRTs provided $4.5^{\circ}$ circular display areas at the usual viewing distance of $114 \mathrm{~cm}$. A Pritchard Spectra Photometer was used to calibrate the luminance and contrast of the displays [contrast $=\left(L_{\max }-L_{\min }\right) /\left(L_{\max }+L_{\min }\right)$, where $L_{\max }$ and $L_{\min }$ represent the maximum and minimum luminances of the grating, respectively].

Sinusoidal grating patterns were generated with a microprocessor-based function generator (Innisfree, Picasso, Cambridge, MA) that was controlled by a DEC PDP $11 / 73$ computer. Each display consisted of a $256-$ line raster that was presented at a $100-\mathrm{Hz}$ frame rate. Stimulus orientation, direction of drift, spatial frequency, contrast, and relative spatial phase could be controlled independently for each CRT. Drifting stimuli that produced a constant temporal frequency of stimulation (typically $3.12 \mathrm{~Hz}$ ) were employed in all experiments.

\section{Response analysis and experimental design}

Action potentials were compiled into peristimulus time histograms (PSTHs) that had 10-ms binwidths. To minimize the potential confounding effects of short-term variations in the responsiveness of cortical neurons, the data for a given experiment (e.g., the stimuli for a spatial frequency tuning function) were collected with the use of a multiple-histogram technique (Movshon et al. 1978). Specifically, the stimuli for the experiment were presented multiple times in a randomly ordered sequence for relatively short periods (e.g., 10 cycles of a grating were drifted across the receptive field). During a given experiment, the re-randomized stimulus sequence was usually repeated three to six times, producing PSTHs for each stimulus that represented the neuron's response to 30-60 stimulus cycles. The amplitudes and phases of the appropriate temporal-response components in the PSTHs were determined by Fourier analysis. Zero-contrast control stimuli were included in all experiments to provide a measure of the neuron's maintained firing rate.

Neurons were classified as simple or complex on the basis of the temporal characteristics of their response to a drifting grating of the optimal spatial frequency and orientation (Skottun et al. 1991). For all subsequent analyses, the amplitude of the first harmonic component was used as the response measure for simple cells, whereas, for complex cells, the amplitude of the DC compo- 
nent (i.e., the average discharge rate) was used as the measure of response strength.

Binocular interactions in cortical neurons were investigated with the use of a dichoptic disparity tuning paradigm similar to that described by Freeman and Robson (1982) and used extensively by Ohzawa and Freeman (1986a,b) to study cortical binocularity in the cat. This paradigm requires a knowledge of key monocular response properties. Therefore the orientation and spatial frequency tuning characteristics of both eyes were determined before the dichoptic experiments. The optimal stimulus orientations and the preferred directions of stimulus movement were typically determined by measuring full orientation response functions. For these experiments, the stimulus spatial frequency was set to the optimal value determined qualitatively and responses for each eye were measured for 12 different orientations that ranged from 0 to $165^{\circ}$ in $15^{\circ}$ steps. At each orientation, responses were obtained for both directions of drift. Next, the optimal spatial frequency was determined by measuring spatial frequency response functions with the use of the optimal stimulus orientations and directions of drift. Responses were typically measured for 13 different spatial frequencies that ranged from 0.2 to 12.8 cycles/deg in 0.5 -octave steps. Finally, the selectivity of a neuron for retinal disparity was determined by measuring the cell's responses as a function of the relative interocular spatial phase of dichoptic grating pairs. We made no attempts to determine a cell's absolute disparity preference. In these experiments, drifting grating stimuli of the optimal spatial frequency were presented at the optimal orientation and direction of drift. Typically responses were collected for 16 dichoptic grating pairs that had different relative interocular spatial phases. The range of spatial phase differences varied from 0 to $360^{\circ}$ in $22.5^{\circ}$ steps. In addition, monocular stimuli for each eye and one blank control ( 0 contrast) were included in the parameter file to provide important reference data. In all of the above experiments, the stimulus temporal frequency was typically $3.12 \mathrm{~Hz}$ and the contrast was held constant, usually at 0.3 .

For descriptive and analytic purposes, the disparity tuning functions were fit with a single cycle of a sine wave (Ohzawa and Freeman 1986a). The sine wave's amplitude was used to calculate the degree of binocular interaction [binocular interaction index $(\mathrm{BII})=$ amplitude of the fitted sine wave/average binocular response amplitude]. A signal-to-noise ratio ( $\mathrm{S} / \mathrm{N}=$ amplitude of the fitted sine wave/residual root mean square error of the fit) was calculated to determine the adequacy of the fitted sine wave in describing a cell's phase tuning characteristics.

Despite the use of anesthetic and paralyzing agents, it is well known that an animal's eyes will move slowly over the course of a recording experiment (Ferster 1981). Interocular differences in eye movements in the direction perpendicular to a cell's optimal orientation, if they occurred during the dichoptic experiments, could affect the shape of the cell's phase tuning function. Fortunately, the interocular phase tuning experiments could be completed in a relatively short period of time (6-8 $\mathrm{min})$, thus reducing the opportunity for residual eye movement to produce spurious results. However, several observations suggested that residual eye movements did not confound the phase tuning experiments. First, for a number of units, the phase tuning experiments were repeated a second time, often with a substantial time interval between the repetitions. In every instance there was good agreement between the two disparity tuning functions. Second, for simple cells, it was possible to monitor the PSTHs for monocular stimuli during the course of the experiments. Significant eye movements, which would have produced relative shifts in response phase, were not observed.

\section{RES ULTS}

We attempted to study every isolated neuron during a given penetration. However, we did not attempt to optimize either the length or the width of the grating stimuli for individual neurons. Therefore the grating stimuli were not effective for neurons with certain response properties (e.g., strongly end-inhibited neurons ). In addition, the small neurons in layer IVC were not as readily isolated as neurons in the supra- or infragranular layers and the spikes from layer IV units were often lost before all of the required experiments were finished. Consequently, the data presented here do not represent a true random sample of striate cortical neurons. Altogether, quantitative data were obtained from a total of 239 cortical neurons: 107 simple cells (45\%) and 132 complex cells $(55 \%)$. Although the majority of neurons was isolated in the operculum and had receptive field eccentricities between 1.5 and $4^{\circ}$, a number of neurons with receptive field eccentricities between 10 and $30^{\circ}$ was isolated in penetrations that entered the striate cortex buried in the calcarine fissure.

\section{Sensitivity to relative interocular spatial phase: simple cells}

The basic data set obtained for a binocular simple cell is illustrated in Fig. 1. This neuron was dominated by the ipsilateral eye and showed a high degree of orientation selectivity, but little direction selectivity (Fig. 1A). In both eyes, the optimal orientation was near the $45-225^{\circ}$ axis and, at the optimal stimulus orientation, both eyes demonstrated a peak spatial frequency of 2.0 cycles/deg and the band-pass spatial frequency tuning characteristics (Fig. $1 B$ ) that are typical of cortical simple cells (DeValois et al. 1982). For dichoptic grating pairs that consisted of the optimal monocular stimuli, the cell's responses varied systematically as a function of the relative interocular spatial phase disparity (Fig. 1C). As illustrated by the representative PSTHs, this neuron's responses were highly modulated and the maximum binocular response amplitude was obtained near a relative phase difference of 0 . As the relative spatial disparity was increased toward a phase difference of $180^{\circ}$, the response amplitude decreased, becoming essentially 0 for relative phase differences between $\sim 135$ and $225^{\circ}$. Thereafter, the response increased as a function of relative phase, reaching the maximum near $360^{\circ}$. The variation in the binocular response amplitude as a function of relative phase disparity was reasonably well described by a sine wave, although clear departures between the data and the fitted function occurred when the binocular response reached values near 0. Some departures are expected on theoretical grounds (Ohzawa and Freeman 1986a); however, in this instance, they can largely be attributed to the fact that this cell had a relatively high activation threshold.

Several points should be noted in the phase tuning data obtained from this typical simple cell. First, the responses produced by the monocular stimuli that were interleaved with the dichoptic stimuli (Fig. $1 C, \triangle$ and $\nabla$ on right axis ) were substantially lower in amplitude than those recorded during the monocular measures of the cell's spatial frequency response function. As previously observed in the cat (Ohzawa and Freeman 1986a), the effective degree of contrast adaptation for cortical neurons is apparently higher during dichoptic experiments. As a result, the response amplitudes for monocular stimuli that are interleaved with the binocular stimuli are typically smaller than those produced 

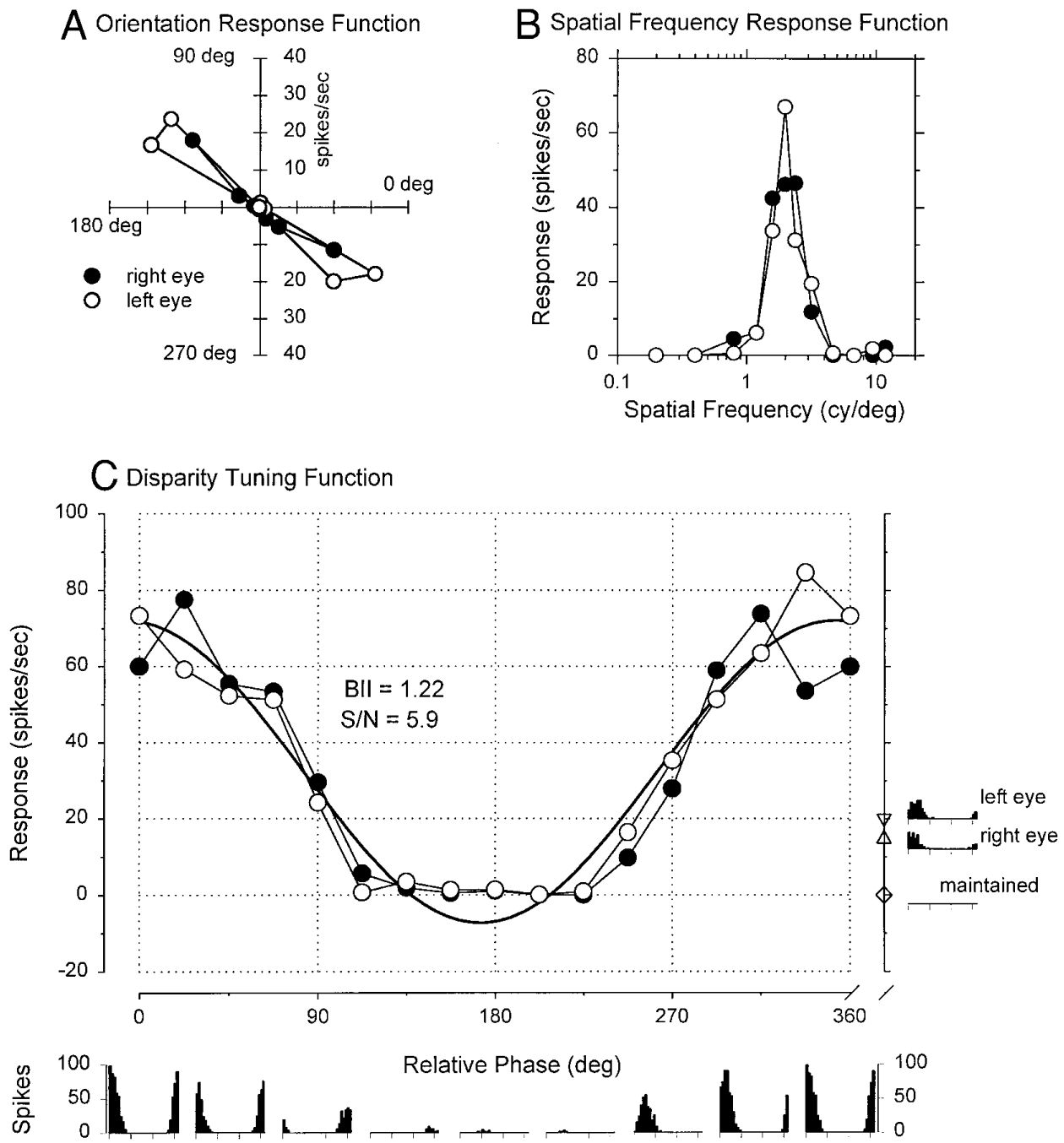

FIG. 1. Basic data set for representative simple cell. $A$ : orientation response functions plotted on a polar coordinate system for the right (filled circles) and left eyes (open circles). Response for a given grating orientation and direction of drift are represented as vectors. Amplitude of fundamental Fourier response (F1, spikes/s) is represented by distance from the origin, and angular position represents direction of drift. Spatial frequency, temporal frequency, and contrast of the gratings were 3.0 cycles $/ \mathrm{deg}, 3.12 \mathrm{~Hz}$, and 0.3 , respectively. $B$ : spatial frequency response functions for the right and left eyes. F1 response amplitude is plotted as a function of stimulus spatial frequency in cycles $/ \mathrm{deg}$ (direction of drift $=135^{\circ}$ ). $C$ : disparity tuning function. F1 response amplitude is plotted as a function of the relative interocular spatial phase difference between the dichoptic grating pairs. Data are shown for 2 identical experiments (direction of drift $=135^{\circ}$, spatial frequency $=2.0$ cycles $/$ $\mathrm{deg}$ ); the 2nd experiment (open circles) was conducted $45 \mathrm{~min}$ after the 1 st experiment (filled circles). Smooth function represents sinusoid fitted to the binocular data for the 1st disparity tuning experiment. Calculated binocular interaction index (BII) was 1.22 and signal-to-noise ratio $(\mathrm{S} / \mathrm{N})$ was 5.9. The cell's maintained firing rate $(\diamond)$ and the monocular response amplitudes $(\nabla$, left eye; $\Delta$, right eye) measured during the phase tuning experiment are shown on the right ordinate. Representative peristimulus time histograms (PSTHs) obtained for the dichoptic stimuli at every other relative spatial phase are shown below the abscissa; PSTHs for the monocular left- and right-eye stimuli and the 0-contrast control (i.e., maintained activity) are shown next to the right ordinate. $X$-axis for each PSTH: $320 \mathrm{~ms}$.

by the same stimuli during the monocular experiments. Second, the binocular response amplitude cannot be predicted simply on the basis of the monocular responses. For example, at the optimum spatial phase, the binocular response was larger than the sum of the two monocular responses, i.e., the cell exhibited binocular facilitation. However, at the relative phase $180^{\circ}$ from the optimal value, the binocular response was lower than the larger monocular response, i.e., the cell exhibited binocular suppression. Third, the binocular data were very repeatable. The open and filled circles in Fig. $1 C$ represent the results from two separate experiments. Although the second experiment was conducted $\sim 45 \mathrm{~min}$ after the first experiment, the data from the two experiments overlapped across the entire range of spatial phases.

The great majority of simple cells showed dichoptic phase tuning functions that were qualitatively similar to those shown in Fig. 1. The exact degree of modulation found in the phase tuning function, as reflected by the BII values, and the relationship between the amplitudes of the monocular responses and the maximum and minimum binocular responses varied from cell to cell. Figure 2 shows the phase tuning functions for six simple cells that were selected to illustrate the range of binocular interactions that we observed. The calculated BIIs varied from a relatively low 

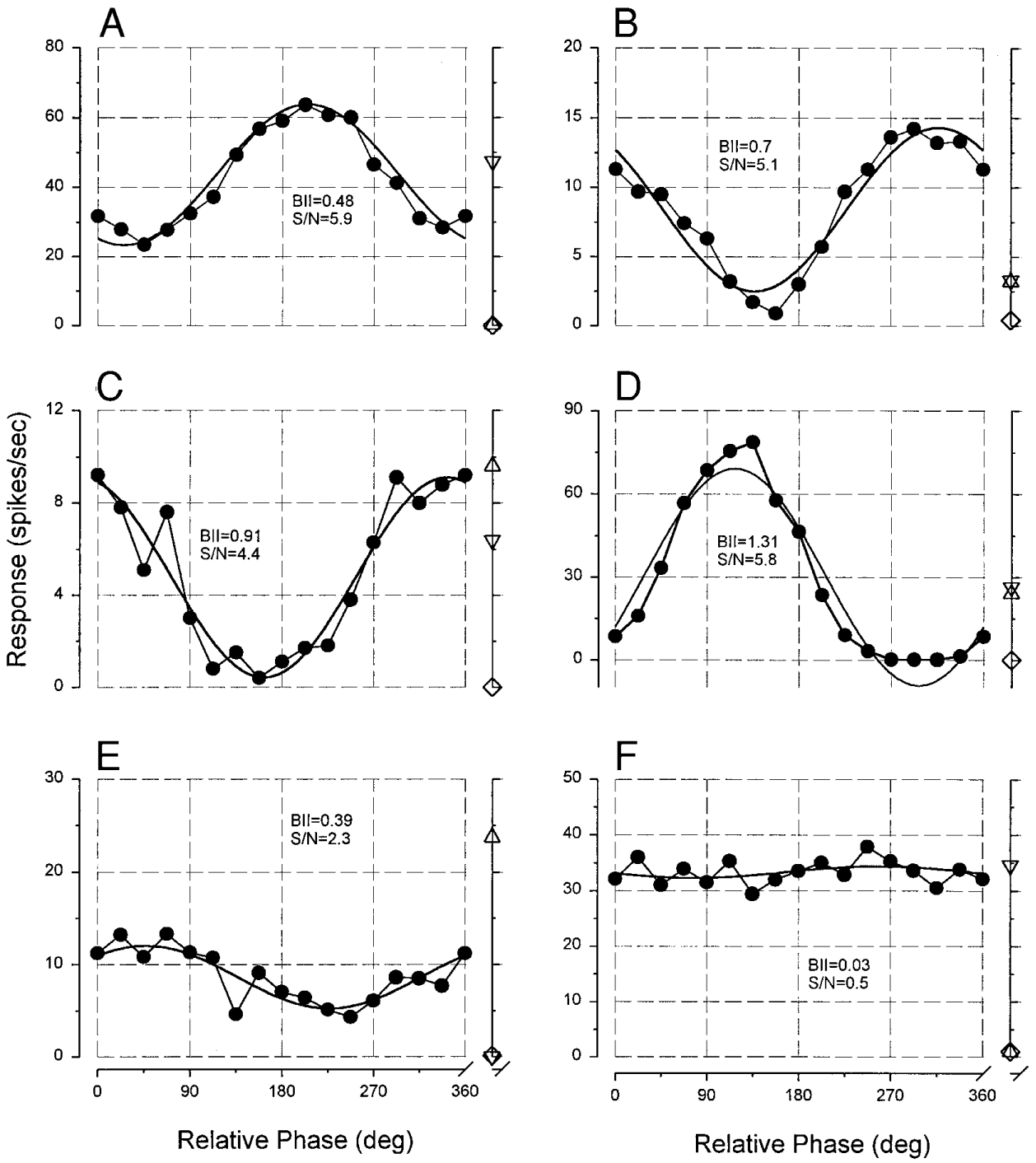

FIG. 2. Binocular phase tuning functions for 6 representative simple cells. Format is similar to that used in Fig. 1C. Filled circles: binocular data. Base-up and base-down triangles: left- and right-eye monocular response amplitudes, respectively. Open diamonds: level of spontaneous activity. Calculated BII and S/N are given for each cell.

value of 0.03 that was obtained from a monocular cell that showed no evidence of binocular interactions (Fig. $2 F$ ) to a relatively high value of 1.31 (Fig. $2 D$ ). Most binocular simple cells showed both binocular facilitation and binocular suppression (Fig. 2, $A, B$, and $D$ ). However, other simple cells (Fig. 2, $C$ and $E$ ), some of which showed robust monocular responses from each eye, were dominated by binocular suppression.

\section{Sensitivity to relative interocular spatial phase: complex cells}

Figure 3 illustrates the basic data set obtained for a complex neuron. The cell was selective for both stimulus orientation and the direction of drift (Fig. 3A) and the left- and right-eye monocular responses produced by optimal stimuli (Fig. $3 B$ ) were very similar in amplitude. During the dichoptic phase tuning experiment, the PSTHs were dominated by the DC Fourier component, the amplitude of which varied systematically with the interocular phase disparity. The dis- parity tuning function for this cell demonstrated a relatively high degree of modulation ( $\mathrm{BII}=0.81, \mathrm{~S} / \mathrm{N}=6.3$ ) and showed both binocular facilitation and suppression.

The disparity tuning function shown in Fig. 3 is very similar in nature to those exhibited by the majority of simple cells. However, the binocular interactions observed in complex cells were, in general, more heterogeneous than those found in the simple cell population. Disparity tuning functions for six representative complex cells are shown in Fig. 4. The four units illustrated in Fig. 4, $A-D$, all had balanced ocular dominances; the monocular responses were clear and unambiguous and, for each unit, the left- and right-eye response amplitudes were very similar. The degree of modulation observed in the disparity tuning functions, however, varied substantially between units, with BII values ranging from 1.32 (Fig. $4 A$ ) to 0.08 (Fig. 4D). However, for most units the disparity tuning functions were well fit by a sine wave. The prominence of binocular facilitation and binocular suppression also varied from unit to unit. For example, the cells in Fig. 4, $A$ and $B$, showed both binocular facilitation 
A Orientation Response Function

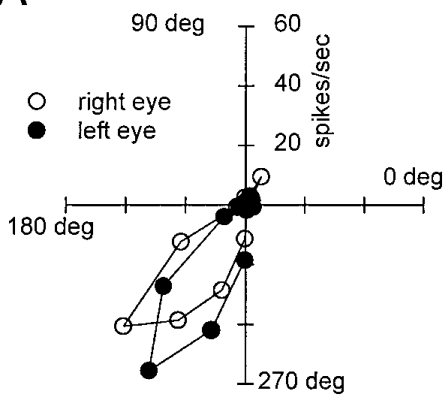

B Spatial Frequency Response Function

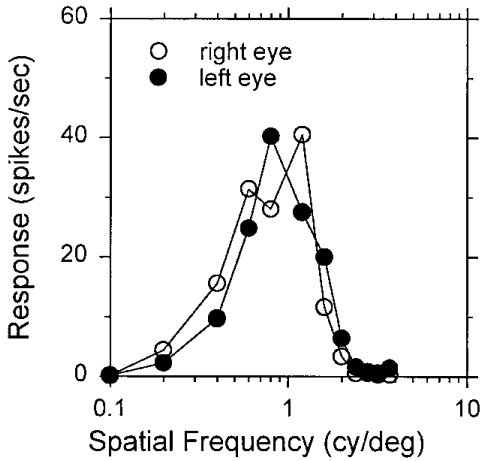

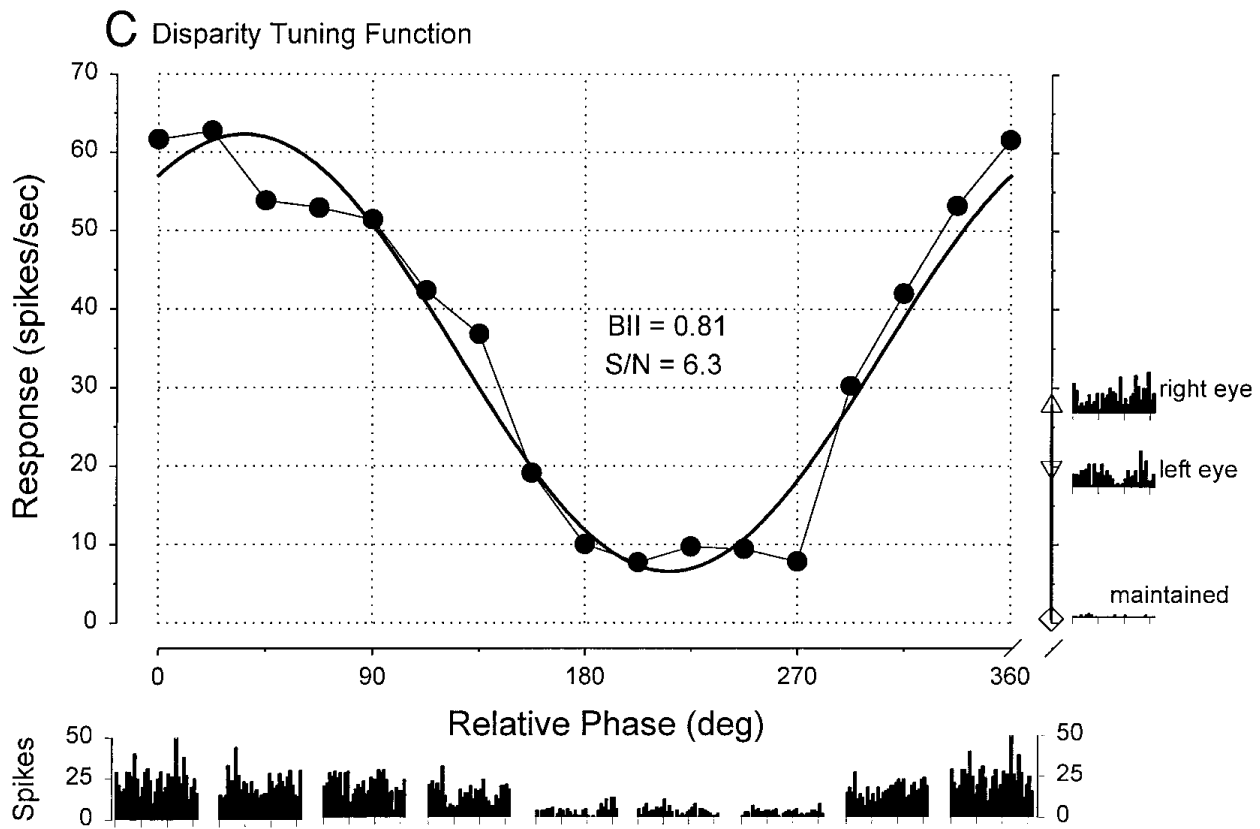

FIG. 3. Basic data set for representative complex cell. Cell's average firing rate (i.e., Fourier F0 or DC component) was used as the measure of response amplitude. $A-C$ : respectively, orientation response functions, spatial frequency response functions, and a disparity tuning function obtained with the use of the optimal monocular stimuli. See Fig. 1 for other details.

and suppression. Other cells (Fig. 4, $C$ and $D$ ) were dominated by cooperative binocular interactions; the binocular responses were either equal or larger than either of the monocular responses at all relative phase differences. In contrast, as shown in Fig. $4 E$, binocular suppression was the prominent feature of some units. The unit in Fig. $4 E$ was only weakly excited by monocular stimuli presented to the nondominant left eye. But, under dichoptic stimulus conditions, the binocular responses were consistently below the better monocular response. And finally, as shown in Fig. $4 F$, some cells showed no obvious binocular interactions for dichoptic stimulation. This cell was driven well by monocular stimuli presented to either eye; however, the binocular response amplitude was independent of relative spatial phase and the average binocular response was equivalent to the better monocular response. This response pattern was never observed in simple cells.

\section{Repeatability of binocular phase tuning measures}

Figure 5 demonstrates the repeatability of the BII values for individual neurons $(n=40)$. The BII values calculated for our basic disparity tuning experiments are plotted against the values obtained in subsequent repeat experiments on the same cell. Identical stimulus parameter files were used for both experiments. With one exception, a cell that had a relatively low response rate and an erratic maintained firing rate, there was very close agreement between the two BII measures. The degree of concordance was high for all BII levels ( slope $=0.86, R=0.93$ ), even though the second BII measure was in some cases obtained several hours after the first measure.

\section{Prevalence of binocular spatial phase selectivity}

For simple cells, the degree of modulation in the disparity tuning function was typically larger than that for complex cells. Figure 6 shows the BII distributions for our simple $(C)$ and complex $(D)$ cell populations. The filled bars represent cells that were consistently monocular. These cells were excited only through one eye during all of the monocular experiments and failed to exhibit any influence from the nondominant eye during the dichoptic experiments. For the binocular simple cell population (open bars), the distribu- 
A

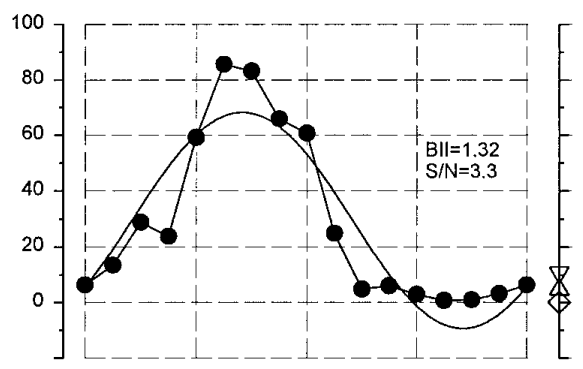

C

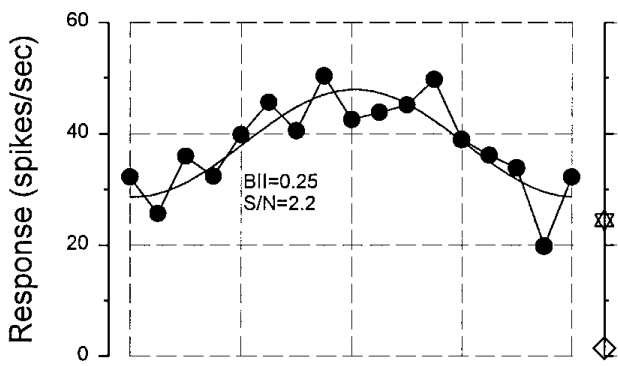

E

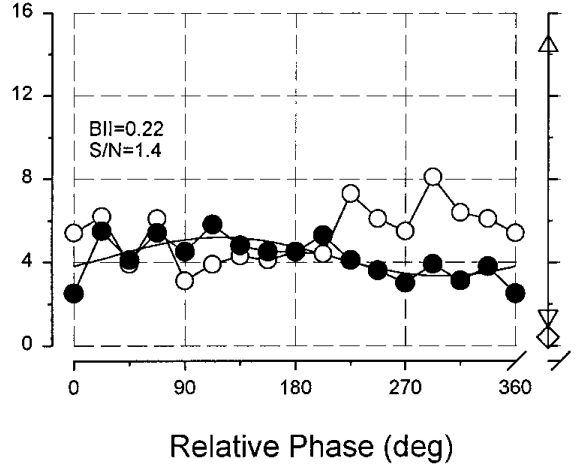

IB

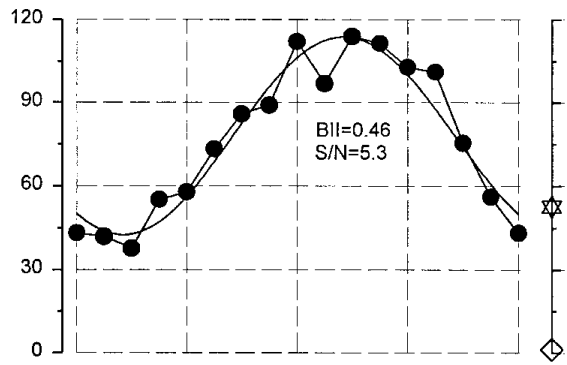

D

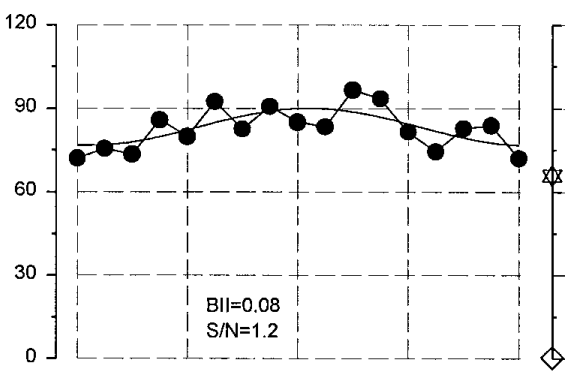

$\mathrm{F}$

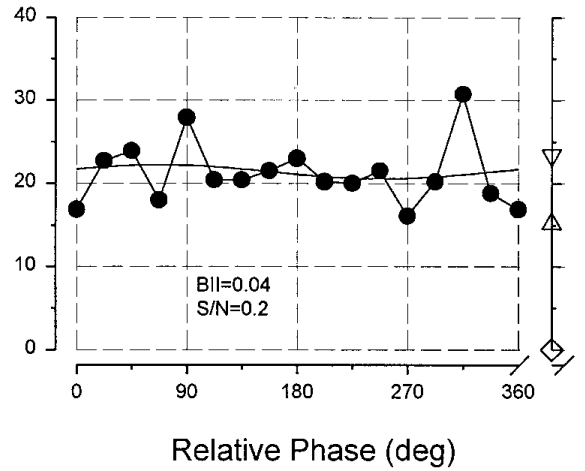

FIG. 4. Binocular phase tuning functions for 6 representative complex cells. See Fig. 2 for other details.

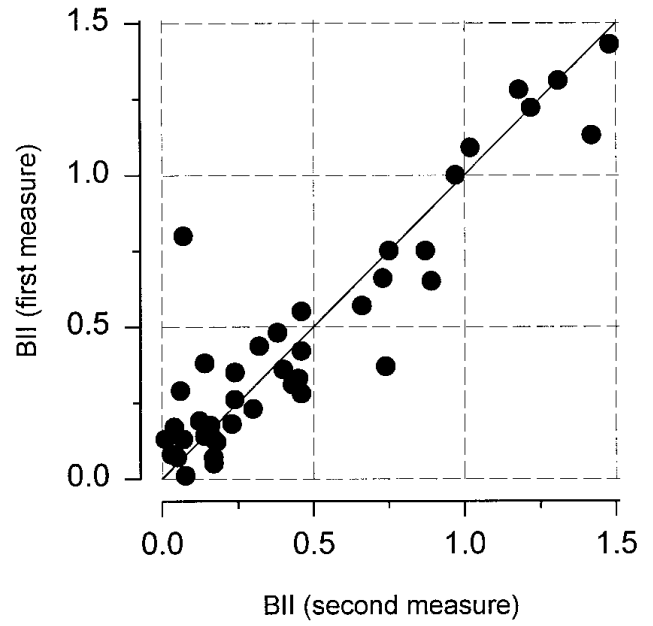

FIG. 5. Comparison of BII values calculated from 2 separate phase tuning experiments for individual cells. The 1 st and 2 nd phase tuning experiments were conducted with the use of identical stimulus parameter files. The time separating the 2 experiments varied from $15 \mathrm{~min}$ to over several hours. tion is relatively broad with a median BII value of 0.54 . Seventy percent of the simple cells had BII values $>0.3$. The range of BII values obtained in the complex cell sample was comparable with that for simple cells. However, the complex cell distribution was narrowly peaked at BII values $<0.1$ and the distribution fell rapidly and monotonically. The median BII value was 0.24 and only $40 \%$ of the complex cells had BII values $>0.3$. But, a lower proportion of complex cells was classified as truly monocular.

For comparison purposes, the distribution of BII values obtained for cat cortical neurons with the use of identical methods and instrumentation (Chino et al. 1994) is also shown in Fig. 6. The BII values for both the cat and monkey ranged between 0 and $\sim 1.5$ and, in both species, simple cells typically showed a higher degree of phase tuning than complex cells.

In the cat, Ohzawa and Freeman (1986a,b) classified cells as either phase specific or non-phase specific with the use of boundary values for BII and $\mathrm{S} / \mathrm{N}$ of 0.3 and 2.0 , respectively. On the basis of BII values alone, the majority of complex cells $(60 \%)$ would be classified as non-phase specific. However, the distribution of BII values does not suggest that this criterion identifies two distinct complex cell 

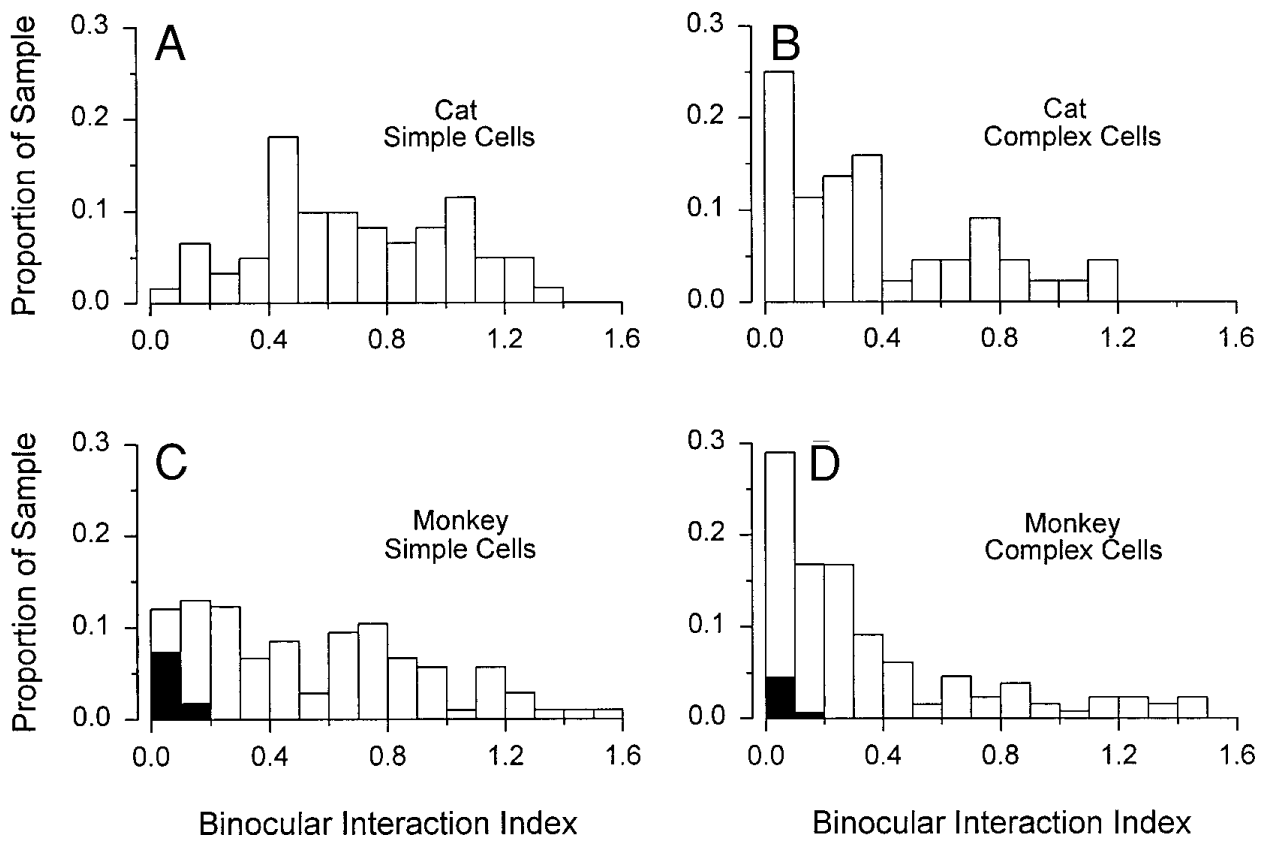

FIG. 6. Comparison of distributions of BII values for monkey (bottom) and cat (top). Left: data for simple cells. Right: data for complex cells. Cat data are from Chino et al. (1994) and were obtained with the use of the same equipment and methodology that were employed in this study. For monkey data, filled and open bars represent monocular and binocular neurons, respectively.

populations. On the other hand, the majority of simple cells $(70 \%)$ would be classified as phase specific, and there is a suggestion of a second peak in the simple cell distribution near BII values of 0.8 .

\section{Binocular phase tuning vs. ocular dominance}

The relationship between a cell's ocular dominance and the degree of binocular interaction (BII) produced by dichoptic stimulation is shown in Fig. 7. The relative strengths of the right- and left-eye inputs to a given neuron were quantified with the use of an ocular dominance index (ODI) that was defined as the response amplitude for the ipsilateral eye divided by the sum of the ipsi- and contralateral eye responses. For simple cells (Fig. 7, left) the degree of binocular interaction was generally stronger for neurons that had relatively balanced ocular dominances.
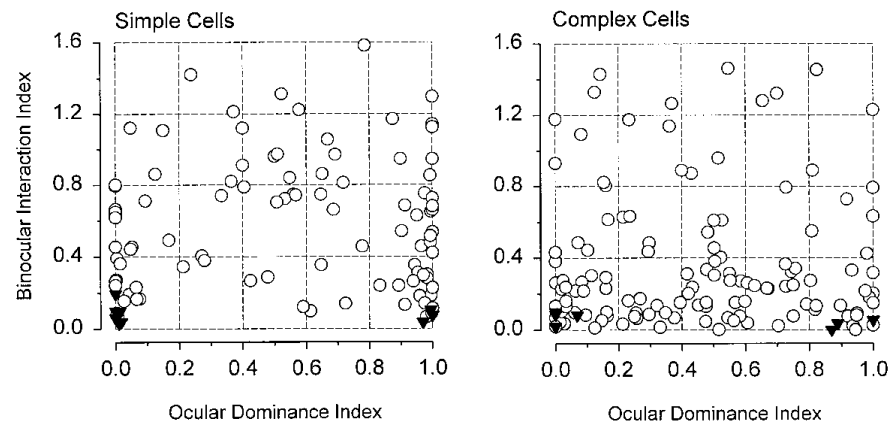

FIG. 7. Scatter plots of BII and ocular dominance index (ODI) for individual simple (left) and complex cells (right). For a given cell, ODI values were calculated with the use of the monocular left- and right-eye response amplitudes obtained during the dichoptic phase tuning experiment (ODI $=$ ipsilateral response/sum of ipsi- and contralateral eye responses $)$. Circles and triangles: binocular and "truly" monocular cells, respectively.
The average BII value for simple cells that had ODI values in the middle third of the index scale (i.e., ODI values from 0.33 to 0.67 ) was 0.77 . Only two simple cells in the middle third had BII values under 0.3 and, in both instances, these units were weakly driven by all grating stimuli. In contrast, binocular simple cells with ODI values in the lower and upper thirds of the scale range had average BII values of 0.50 and 0.55 , respectively. Including simple cells that appeared to be monocular on all tests (filled triangles) reduces these average BII values to 0.42 and 0.52 , receptively. Although some binocular simple cells with asymmetric ocular dominances (ODI $<0.33$ or $>0.67$ ) demonstrated high degrees of binocular interaction, $43 \%$ demonstrated $\mathrm{BII}$ values $<0.3$.

BII values did not vary in a systematic fashion with ocular dominance in complex cells (Fig. 7, right). The average BII values for the lower, middle and upper ODI ranges were $0.35,0.40$, and 0.38 , respectively. Moreover, the range of BII values for complex cells was comparable for all ODI values.

\section{Binocular phase tuning: effects of orientation}

Because orientation is a critical stimulus feature for cortical neurons, we investigated the effects of interocular differences in stimulus orientation on the phase tuning functions of cortical neurons and the relationship between the degree of phase selectivity and a cell's orientation tuning characteristics. Figure 8 illustrates the effects of interocular orientation differences on the binocular phase tuning function of a cortical neuron. This phase-specific complex cell showed a high degree of orientation and direction selectivity, and, as with the majority of cortical neurons, the optimum stimulus orientations for the two eyes were very similar. Binocular phase tuning functions (Fig. 8A) were measured when the 

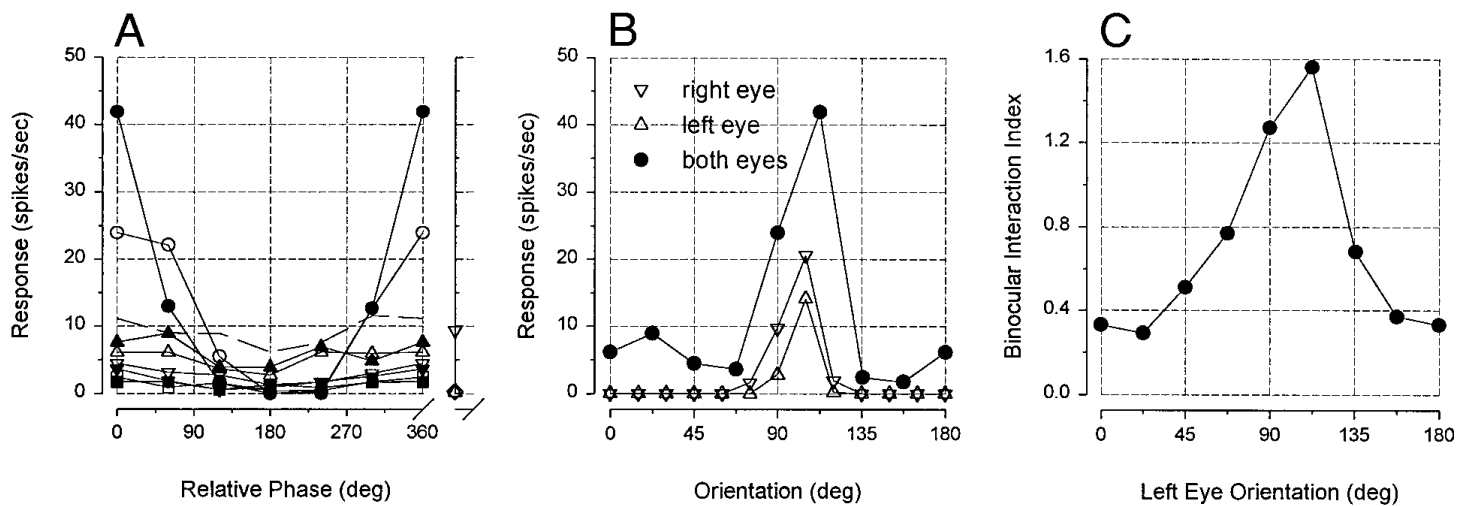

FIG. 8. Effects of interocular differences in stimulus orientation on binocular interactions for a phase-selective complex cell. A: binocular phase tuning functions obtained with optimal orientation for the right eye $\left(105^{\circ}\right)$; the left-eye orientation was set to either $0^{\circ}(\square), 22.5^{\circ}(\bullet), 45^{\circ}(\triangle), 67.5^{\circ}(\Delta), 90^{\circ}(\circ), 112.5^{\circ}(\bullet), 135^{\circ}(\nabla)$, or $157.5^{\circ}(\nabla)$. Dashed line: monocular responses for the right eye. $B$ : largest binocular response amplitude plotted as a function of stimulus orientation for the left eye. Also shown are the monocular orientation response functions for the left and right eyes. $C$ : BII values for the phase tuning functions in A, plotted as a function of the left eye's stimulus orientation.

stimulus orientation for the right eye was set at the optimal value $\left(105^{\circ}\right)$ and the left eye's orientation was varied between 0 and $157.5^{\circ}$ in $22.5^{\circ}$ steps. The binocular response amplitude and the degree of modulation in the disparity tuning function varied systematically with the stimulus orientation for the left eye. The largest binocular response was obtained when the left eye's orientation was at $112.5^{\circ}$ (Fig. $8 B$ ), which was the stimulus orientation closest to the cell's optimal orientation. The close agreement between the shapes of the "binocular" and monocular orientation response functions indicate that, as in the cat (Nelson et al. 1977), the influence of interocular orientation differences on a cell's binocular response largely reflects the cell's monocular orientation tuning characteristics. The degree of modulation in the phase tuning function (Fig. $8 C$ ) was also influenced in a similar manner.

A simpler paradigm was used to assess the effects of stimulus orientation on binocular interactions in 28 units. We compared the phase tuning functions measured when the stimuli for both eyes were presented at their optimal orientations and when the stimuli for one eye were presented at an orientation $90^{\circ}$ from the optimal orientation. Figure 9 shows representative results for a simple cell (Fig. 9A) and a complex cell (Fig. 9B). Both cells were well tuned with respect to orientation and direction of movement. For the optimal stimulus orientations (filled circles), the phase tuning functions were highly modulated. In both cases, the cells exhibited binocular facilitation at the optimal relative phases and binocular suppression for phase angles $180^{\circ}$ away from the optimal phase. When, however, the stimulus for one eye was presented at an orientation orthogonal to the optimal value, there was a clear reduction in binocular interactions (open circles) and the binocular responses assumed an amplitude equivalent to the monocular response for the eye viewing the optimal stimulus orientation. The BII values for the optimal and orthogonal stimuli, respectively, were 0.99 and 0.17 for the simple cell and 1.32 and 0.12 for the complex cell. As shown in Fig. 9C, a similar pattern of results was obtained for every cell that was tested.

Cells with optimal orientations near vertical are well suited for detecting the horizontal disparity cues that support stereopsis (Orban 1991). Therefore we examined the possibility that the degree of binocular interactions revealed by our binocular phase tuning experiments varied in a systematic fashion with the orientation tuning characteristics of cortical neurons. In Fig. 10, the BII values for individual
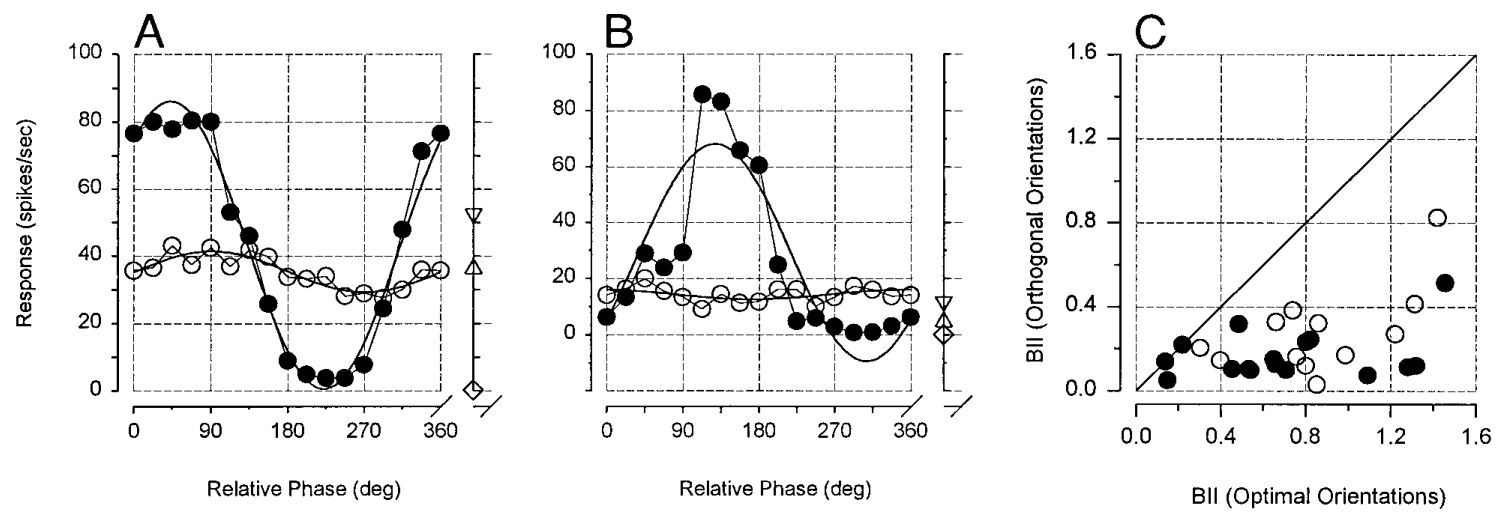

FIG. 9. Representative examples of phase tuning functions obtained for a simple cell $(A)$ and a complex cell $(B)$ when grating stimuli were oriented optimally for both eyes (filled circles) and when the stimuli for 1 eye were presented $90^{\circ}$ away from optimal orientation (open circles). $C$ : comparison of BII values for phase tuning functions obtained when optimally oriented stimuli were presented to both eyes and when stimuli presented to 1 eye were oriented $90^{\circ}$ from optimal value. Open and filled circles: simple and complex cells, respectively. 
neurons are plotted as a function of optimal orientation $(A)$, orientation tuning bandwidth $(B$, full width at 0.5 the maximum amplitude), and directional index determined from the dominant eye's orientation response function $[C$, directional index $=$ (response amplitude in the optimal direction response amplitude for the opposite direction)/(sum of responses for the optimal and opposite directions)]. For both simple $(\bigcirc)$ and complex $(\boldsymbol{\square})$ cells, the degree of modulation in the binocular phase tuning function was independent of either the cell's optimal stimulus orientation (Fig. 10A) or its degree of directional selectivity (Fig. 10C). There was an association between orientation tuning bandwidth and BII. Specifically, cells that had relatively high BII values tended to have narrow orientation tuning functions. For example, $46 \%$ of the cells that had bandwidths $<60^{\circ}$ demonstrated BII values $>0.4$. On the other hand, only $22 \%$ of the cells with broader orientation tuning functions exhibited BII values $>0.4$.

\section{Binocular phase tuning: effects of spatial frequency}

For selected cells, binocular phase tuning functions were measured for a series of different spatial frequencies. The most frequently used stimulus set included four spatial frequencies that bracketed the cell's optimal spatial frequency. During these interleaved experiments, binocular responses were obtained at $45^{\circ}$ phase intervals for each spatial frequency.

The effects of spatial frequency on the binocular phase tuning function of a complex cell are shown in Fig. 11. The cell's optimal spatial frequency was 2.0 cycles/deg (Fig. $11 \mathrm{~A}$ ) and phase tuning functions were measured for spatial frequencies of $0.5,1.0,2.0$, and 4.0 cycles/deg (Fig. 11B). To compare the relative binocular response rates for the different spatial frequencies, the sinusoids that were fit to the individual phase tuning functions were shifted on the abscissa so that the maximum binocular response corresponded to a relative phase angle of $180^{\circ}$. The maximum binocular response rate varied in a manner that was predictable from the cell's monocular spatial frequency response functions. The largest binocular responses and the greatest absolute variations in firing rate as a function of phase were obtained for stimuli near the peak of the spatial frequency response functions. It was also obvious that the relative degree of modulation in the phase tuning function varied with stimulus spatial frequency.

Figure $11 C$ summarizes the effects of spatial frequency on the relative degree of modulation in the phase tuning functions. For almost all of the cells that were tested, BII values were highest for low spatial frequencies and decreased systematically with increases in spatial frequency. In some instances, cells that appeared to be non-phase selective at optimal and higher spatial frequencies demonstrated modulated phase tuning functions for the lower spatial frequencies. These results point out the importance of using consistent criteria for selecting the spatial frequency that is used to measure phase tuning functions.

\section{Binocular phase tuning: effects of stimulus contrast}

The effects of stimulus contrast on phase selectivity are illustrated in Fig. 12. In these experiments, phase tuning functions were measured for five stimulus contrasts in an interleaved manner. The contrast ranged from 4.7 to $30 \%$ in 0.2 -log-unit intervals. Figure $12, A$ and $B$, show the phase tuning functions for a typical simple cell for each contrast level and the monocular and binocular contrast response functions, respectively. Also shown in Fig. $12 B$ are the BII values for each contrast level (open diamonds).

Although for some cells the binocular contrast response function appeared to mirror the monocular response functions (Fig. 12B), as Anzai et al. (1995) found in the cat, the binocular functions typically had steeper slopes than would be predicted from simple summation of the two monocular functions. In addition, the monocular responses often appeared to saturate at lower contrast levels than the binocular response.
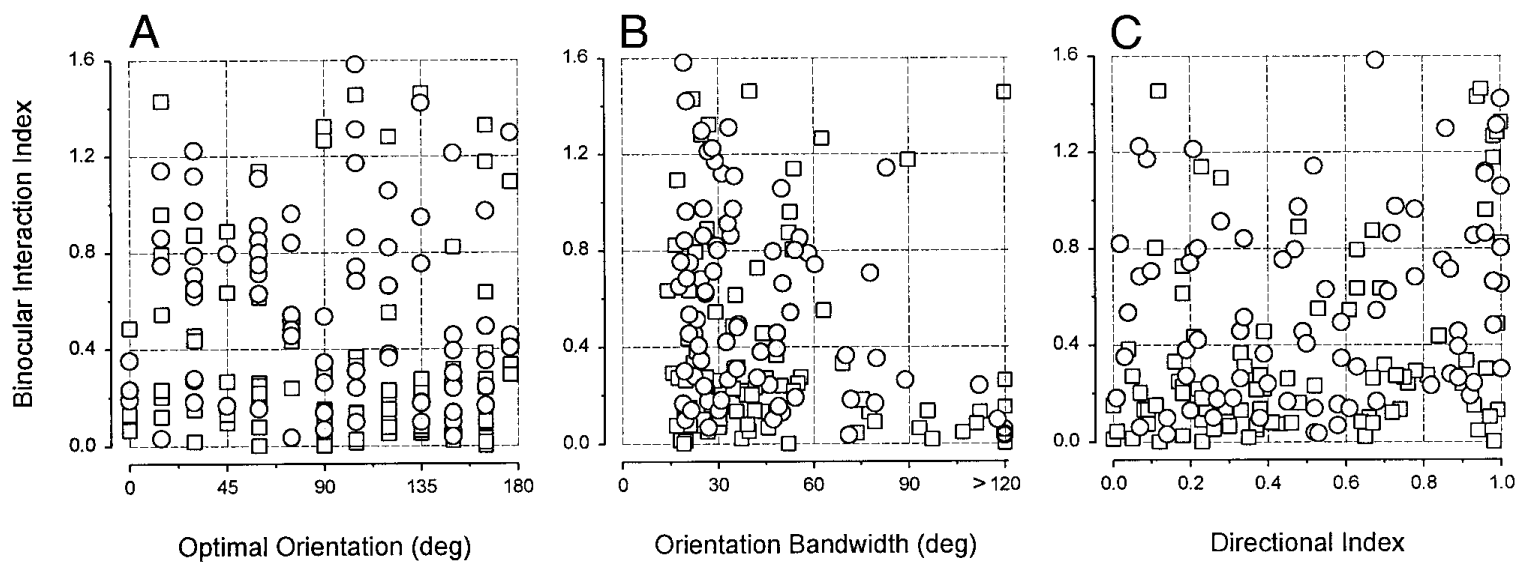

FIG. 10. Associations between degree of binocular interactions measured in binocular phase tuning experiments and orientation and direction tuning characteristics of individual units. $A$ : BII plotted as a function of optimal stimulus orientation for the dominant eye of individual simple $(O)$ and complex $(\square)$ cells. Stimulus orientation is specified with the use of standard ophthalmic axis designations. $B$ : BII plotted as a function of bandwidth of orientation tuning function measured for dominant eye. Bandwidth was defined as the full width of the tuning function measured at a response amplitude equal to half the peak response amplitude. $C$ : BII plotted as a function of the directional index calculated from the dominant eye's orientation response function. Direction index was defined as difference in response amplitudes for optimal and opposite directions of stimulus movement divided by their sum. Direction index value of 0 indicates that the cell responded equally to both directions of drift, whereas a value of 1.0 indicates that the cell responded only to stimuli drifting in 1 direction. 

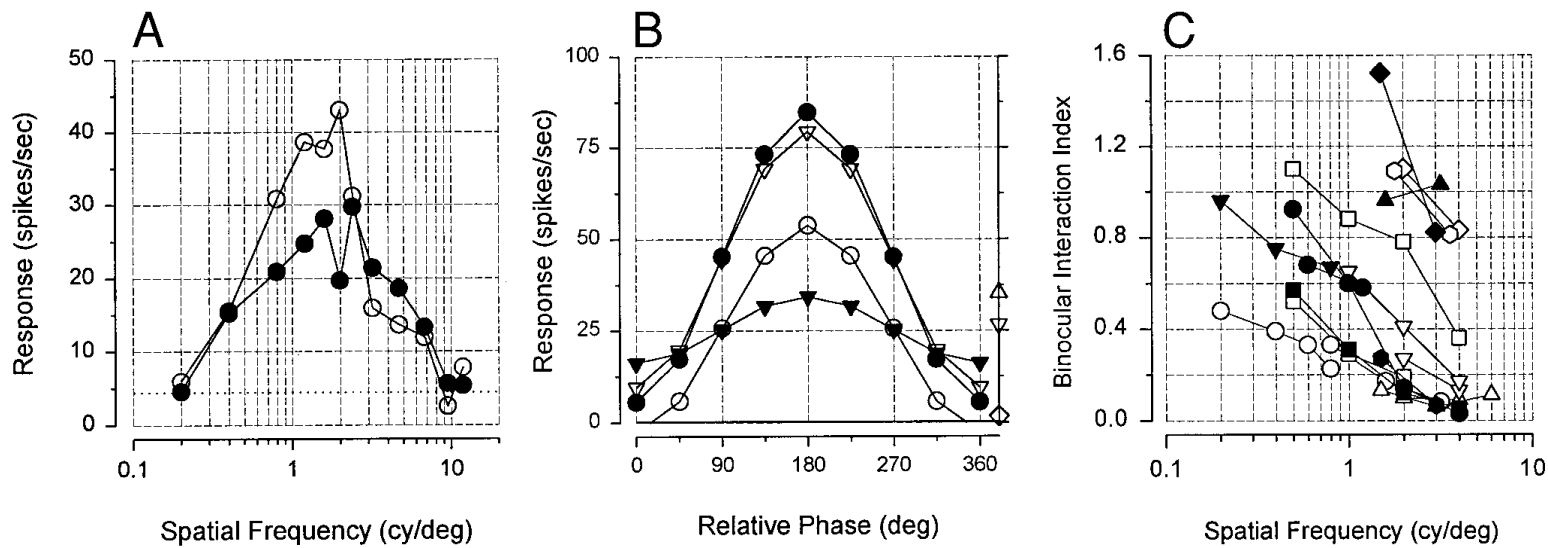

FIG. 11. Effects of stimulus spatial frequency on binocular phase tuning function. $A$ : spatial frequency response functions are shown for the left $(\bullet)$ and right $(O)$ eyes of a representative complex cell. Dotted line: cell's maintained firing rate. $B$ : binocular phase tuning function for stimulus spatial frequencies of 0.5 cycles $/ \mathrm{deg}(O), 1.0 \mathrm{cycles} / \mathrm{deg}(\bullet), 2.0 \mathrm{cycles} / \mathrm{deg}$ $(\nabla)$, and 4.0 cycles/deg $(\mathbf{\nabla})$. Functions were fit with a sinusoid that was then shifted on the phase axis so that the maximum binocular response amplitudes corresponded to a relative phase of $180^{\circ}$. Right ordinate: cell's maintained firing rate $(\diamond)$ and monocular response amplitudes that were obtained with the 2.0 -cycle/deg stimuli ( $\triangle$, right eye; $\nabla$, left eye). $C$ : BII values plotted as a function of spatial frequency for individual neurons $(n=16)$.

The relative degree of modulation in the binocular phase tuning functions and the optimum relative phase for a given cell were unaffected by changes in contrast. As can be seen in Fig. 12C, which presents BII values as a function of contrast for individual neurons $(n=17)$, stimulus contrast did not have a consistent effect on BII values, regardless of the degree of interaction demonstrated by the cell. These results indicate that the failure to find phase selectivity in some cells cannot simply be attributed to a ceiling effect associated with the use of high stimulus contrasts that effectively saturated a cell's response.

\section{Microelectrode track reconstructions}

Neurons that have certain common properties are not distributed randomly throughout the striate cortex, but instead are frequently grouped together in association with anatomically defined structures (Hubel and Wiesel 1968; Livingstone and Hubel 1984). The histological reconstruction of our microelectrode tracks allowed us to identify recording locations and shed some light on the distribution of binocular phase tuning in the striate cortex.

Figure 13 shows an electrode track reconstruction for an obliquely oriented penetration that traveled for $\sim 3 \mathrm{~mm}$ within the upper cortical layers. The schematic drawing in Fig. $13 \mathrm{~A}$ was made from serial sections cut parallel to the surface of the brain and illustrates the electrode track, the locations of lesions, and the laminar borders. Figure 13, $B$ and $C$, shows the positions of isolated units along the track as a function of their ODI and BII, respectively. Ocular dominance varied in a systematic fashion as a function of electrode depth. There were several clear transitions between neighboring ocular dominance columns where the ODI changed from values of 0 to 1.0 and visa versa. The BII also varied as a function of electrode depth in a related manner, with clusters of cells that had relatively high BII values being interspersed between cells with relatively low BII values. A comparison of the functions in Fig. 13, B

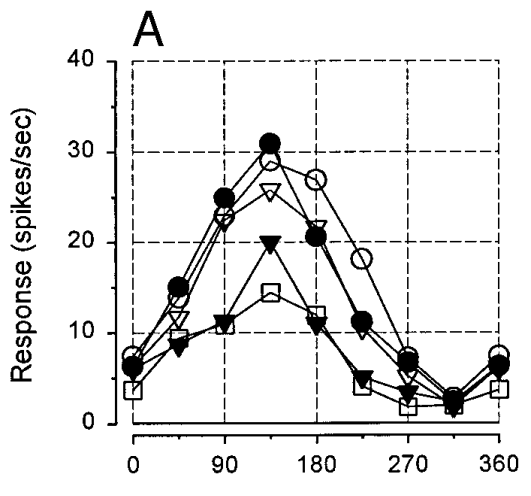

Relative Phase (deg)
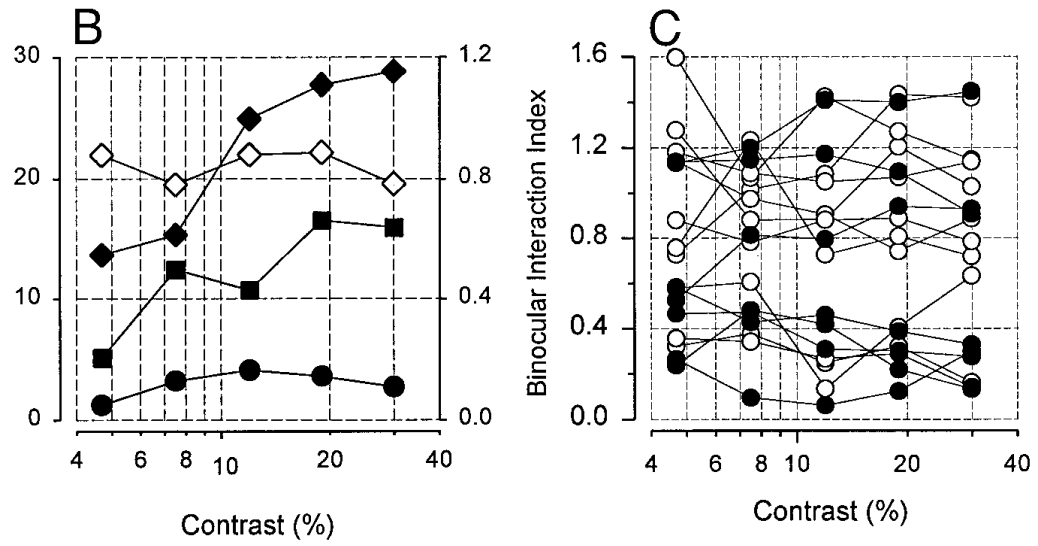

FIG. 12. Effects of stimulus contrast on binocular phase tuning function. $A$ : phase tuning functions for representative simple cell, shown for 5 different stimulus contrasts $(\square, 4.7 \%, \nabla, 7.5 \%, \nabla, 12 \%, \bullet, 19 \%, \circ, 30 \%)$. B: contrast response functions for monocular left-eye $(\bullet)$ and right-eye $(\bullet)$ viewing conditions and for the binocular responses obtained at the optimal interocular spatial phase $(\bullet)$. Open diamonds: BII values determined for each contrast level (right ordinate). $C$ : BII values plotted as a function of contrast for individual neurons $(n=17)$. Filled and unfilled symbols: complex and simple cells, respectively. 
and $C$, shows that the clusters of cells with high BII values were usually found in areas of cortex that exhibited balanced ocular dominances. On the other hand, cells with low BII values were typically located in the centers of the ocular dominance columns, i.e., corresponding to cells that had ODI values near 0 or 1.0 . This pattern of results is in agreement with earlier work in the cat. Specifically, cells that are located at the borders of ocular dominance columns exhibit higher degrees of binocular interaction than cells in the center of ocular dominance columns (Ferster 1981; LeVay and Voigt 1988). It is also interesting that the cells that exhibited the highest BII values in this penetration were located in layer 4B. The second and third lesions (at depths of 1,823 and $2,823 \mu \mathrm{m}$ ) correspond to the approximate borders of layer 4B. Between these two lesions, we encountered the three cells that had the highest BII values. Hubel and Livingstone (1990) have reported that in V1, depth-sensitive neurons are found exclusively in layer 4B.

Experiments in which neurons were sampled through the entire thickness of the striate cortex revealed no apparent differences in the degree of binocular interactions observed in the supra- versus infragranular layers. The range of BII values was comparable for cells above and below layer 4 and, in both regions, cells with high BII values tended to be grouped together. Cells in layer $4 \mathrm{C}$, when they could be isolated and studied, typically had low BII values. In addition, recordings from areas of cortex containing cells that had receptive fields located between 10 and $30^{\circ}$ from the fovea showed that there were no obvious changes in the degree of binocular interactions as a function of receptive field eccentricity.

\section{IS C USSION}

Our results demonstrate that sensitivity to interocular spatial phase disparities is a common property of neurons in the monkey's striate cortex. Over 53\% of our total sample would qualify as phase specific with the use of a criterion BII value of 0.3. Like many other functional response properties, the degree of phase tuning varies from cell to cell in a nonrandom fashion and cells with similar disparity tuning properties tend to be clustered together. A given neuron is more likely to show a higher degree of phase tuning if it is a simple cell; if it has balanced ocular dominance, particularly in the simple cell population; if it is located at the border between adjacent ocular dominance columns; and if it is selective for orientation.

\section{Effects of stimulus variables}

The disparity tuning functions of cortical simple cells can be accounted for by a combination of the monocular receptive field profiles in each eye in both the cat (Ferster 1981; Maske et al. 1986a; Ohzawa and Freeman 1986a,b) and monkey (Smith et al. 1997). Likewise, the left- and right-eye inputs to complex cells appear to a first approximation to be combined in a simple additive fashion (Ohzawa and Freeman 1986a,b; Smith et al. 1997). Consequently, it is reasonable to expect that critical monocular stimulus parameters would also strongly affect the cell's binocular phase tuning function. For a typical cell, the maximum binocular response amplitude and the greatest absolute degree
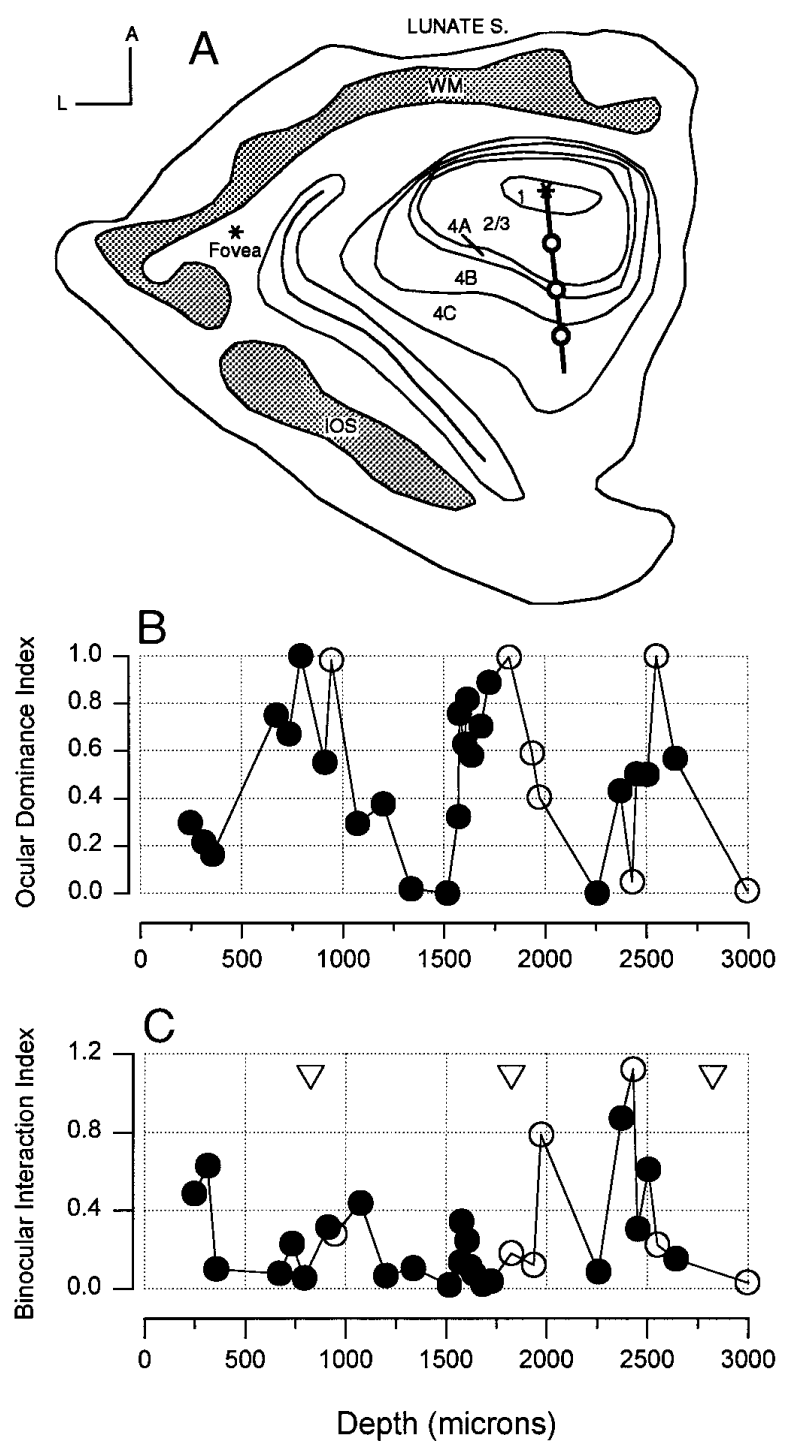

FIG. 13. A: schematic drawing of microelectrode track made from serial sections through primary visual cortex (V1 or striate cortex). Penetration entered the left operculum at an oblique angle and was restricted to the supragranular layers. $B$ and $C$ : ODI and BII values, respectively, plotted as a function of electrode pathlength for individual neurons. Open and filled symbols: simple and complex cells, respectively. Open triangles in $C$ : depths of lesions along electrode track.

of response modulation in the phase tuning functions occurred for dichoptic stimuli composed of the optimal spatial frequency and orientation.

As Nelson et al. (1977) have previously shown for the cat, the binocular orientation response functions for monkey cortical neurons were similar in shape and only slightly broader than their monocular orientation tuning functions. These observations are in agreement with the idea that the mechanisms that mediate binocular excitation and inhibition are both orientation selective (Ferster 1981). And because subcortical neurons show only modest orientation biases (Levick and Thibos 1982; Smith et al. 1990), it is confirmed that the mechanisms that mediate binocular phase sensitivity originate in the cortex (Ferster 1981; Ohzawa and Freeman 1986a).

We did not observe any widespread evidence for interocular suppression for orthogonally oriented stimuli. In one 
sense these results are not surprising because most cortical neurons do not respond to stimuli oriented orthogonal to their preferred orientation. However, these results are interesting because dichoptic grating pairs that have orthogonal orientations produce strong interocular inhibition behaviorally in the form of binocular rivalry (Wolfe 1986). Potential neuronal correlates of binocular rivalry have been described in neurons in the superior temporal sulcus of the macaque monkey (Leopold and Logothetis 1996; Logothetis and Schall 1989) and in the striate cortex (Sengpeil et al. 1995) and the lateral geniculate nucleus (Varela and Singer 1987) of the cat. Ohzawa and Freeman (1986a,b), using similar methods in cats, also failed to observe suppression for orthogonal stimuli. Our stimulus paradigm, which involved relatively brief, interleaved stimulus pairs, may not have been optimal for detecting suppression associated with binocular rivalry. In particular, binocular rivalry is characterized by periodic temporal variations in suppression that take time to develop (Wolfe 1986) and that would tend to be masked by our stimulus paradigm.

The monocular contrast response functions for cortical neurons rise in a monotonic manner and asymptote at high contrasts (Albrecht and Hamilton 1982; Dean 1981; Tolhurst et al. 1981), with the exact contrast level producing response saturation varying substantially from neuron to neuron (Albrecht and Hamilton 1982). It is important to investigate the effects of contrast on the binocular phase tuning function because it is possible that the shape of the function could vary with contrast. If, for example, the contrast that produced response saturation varied as a function of phase disparity, relatively high contrast stimuli would yield artificially flat phase tuning functions. Moreover, when relatively high contrast stimuli are employed, cell-to-cell variations in the saturating contrast level would broaden the range of binocular phase selectivity found in a population of cortical neurons. However, as shown in Fig. 12, the phase tuning of cortical neurons is largely independent of stimulus contrast. Even when response saturation occurs, the shape of the phase tuning function is not changed. These results indicate that response saturation occurs at the same contrast for all interocular phase disparities and that contrast saturation for dichoptic stimuli is not simply determined by a cell's absolute response rate. A comparison of the monocular and binocular contrast response functions emphasizes the fact that the phenomenon of contrast saturation is not dependent on response amplitude (Anzai et al. 1995). Thus, like a cell's orientation selectivity (Sclar and Freeman 1982) and spatial frequency tuning characteristics (Albrecht and Hamilton 1982), disparity selectivity is stable and invariant with respect to stimulus contrast.

\section{Binocular phase selectivity: monkey vs. cat}

If differences in spatial scale are taken into account, the general binocular phase tuning characteristics of monkey striate neurons are similar in most respects to those of cells in area 17 of the cat (Chino et al. 1994; Ohzawa and Freeman 1986a,b). We observed in the monkey all of the different patterns of binocular interactions that have previously been described for the cat. Specifically, most simple and many complex cells showed both phase-dependent binocular facilitation and suppression. Within our sample of non-phase- specific complex cells, binocular responses varied from synergistic to antagonistic, with many cells showing no apparent differences between the binocular and monocular response amplitudes. And, a small proportion of neurons in both species showed no evidence of binocular interactions. We did not observe any cells in the monkey that showed binocular phase tuning functions that were qualitatively different from those observed in the cat (Chino et al. 1994; Ohzawa and Freeman 1986a,b).

There were some quantitative differences between the phase-selective properties of cat and monkey cortical neurons. The average BII values were slightly lower for the monkey, particularly for the simple cell population. This difference probably reflects quantitative differences in the degree of convergence of inputs from the two eyes onto striate neurons. Cortical neurons in the monkey generally show greater asymmetries in ocular dominance than those in the cat (Hubel and Wiesel 1968), especially for the simple cell population and for cells in layer IV. Because cortical neurons, especially simple cells, with unbalanced ocular dominance are more likely to show lower degrees of phase tuning than cells with balanced inputs from the two eyes, the lower average BII values in the monkey appear to reflect relative differences in the balance of monocular inputs onto individual neurons.

\section{Binocular disparity tuning in monkey striate cortex}

The disparity sensitivity of monkey striate neurons has been previously studied in both the anesthetized/paralyzed monkey (Hubel and Livingstone 1987; Hubel and Wiesel 1968) and in the awake/alert monkey (see Poggio 1991). Despite a number of methodological differences, the results of our study are similar to those from previous studies in several respects. As in previous studies, we found that very few neurons were truly monocular; only $7 \%$ of the cells we studied failed to show any signs of binocularity. Poggio (1984) reported that $6 \%$ of their overall sample of V1 neurons were monocular. These percentages are substantially below estimates obtained with monocular measures of ocular dominance (e.g., 42\%, Hubel and Livingstone 1987; 39\%, Hubel and Wiesel 1968). Dichoptic stimuli are more effective in revealing binocular interactions because, in addition to subthreshold inputs being revealed, both excitatory and inhibitory inputs from an eye can be evidenced. With monocular stimulation, a threshold mechanism that is in operation after the convergence of inputs from the two eyes masks weak excitatory inputs from the nondominant eye (LeVay and Voigt 1988; Ohzawa and Freeman 1986a,b; Smith et al. 1997a). This threshold mechanism is the most likely reason for the fact that many cells, which appear to be monocular when each eye is stimulated separately, exhibit robust binocular interactions for dichoptic stimuli, and for the frequent observation that the binocular response amplitude cannot be predicted from the amplitudes of the monocular responses. It is also likely that the phenomenon referred to as "obligate" binocular cells, cells that only respond to dichoptic stimulation (Hubel and Livingstone 1987; Poggio and Talbot 1981), is obtained because a cell has a relatively high threshold.

With respect to the prevalence of disparity-selective neurons in V1, our results are somewhat similar to those of Poggio and Fischer (1977). In both studies, the majority of 
V1 neurons was reported to be disparity selective. Disparityselective cells were found in all cortical layers, although they occurred less frequently in layer 4C. And both simple and complex cells demonstrated disparity selectivity. In contrast, Hubel and Livingstone $(1987,1990)$ found few disparity-tuned cells in layers 2 and 3 and found that all of their clearly "stereo-selective" neurons were complex cells, were orientation selective, and were located in layer 4B. The lower prevalence of disparity-selective cells reported by Hubel and Livingstone can be attributed, in large part, to the relatively strict classification criteria that they employed. They considered cells to be disparity tuned only if the cell's binocular response was clearly different from either monocular response and the sum of the two monocular responses. Many cells in our sample demonstrated a high degree of modulation in their binocular phase tuning function, but did not exhibit binocular response amplitudes greater than the sum of the monocular responses. Although the responses of these cells were clearly dependent on retinal disparity, they would not meet the criterion of Hubel and Livingstone.

In most previous studies, V1 neurons have been categorized into different functional classes on the basis of their optimum disparity (i.e., the location of the best disparity relative to the horopter), the bandwidth and symmetry of their disparity tuning functions, and the nature of the cell's predominate binocular response (i.e., facilitation vs. suppression ). In its most current form, this classification scheme includes six categories of disparity-selective cells and a single class of non-disparity-selective cells (Poggio 1991). Examples of these response types have been found in the cat (Ferster 1981; LeVay and Voigt 1988) and in both the alert (Poggio 1991) and anesthetized/paralyzed monkey (Hubel and Livingstone 1987, 1990). However, in no study is there clear evidence to support the existence of distinct classes of disparity-tuned neurons. In the only study that employed quantitative analysis techniques to examine the discreteness of these categories, LeVay and Voigt (1988) found a broad continuum of disparity tuning properties in the striate cortex of the cat. Because we employed relative disparities rather than absolute stimulus disparities, this classification scheme cannot be directly applied to our data. However, several aspects of our data shed light on this classification scheme.

As shown in Fig. 6, the degree of disparity tuning cannot be used to identify distinct functional classes of cells. The distribution of BII values for complex cells was unimodal and there were no obvious differences between cells with low vs. high BII values. There is some suggestion of two different peaks in the BII distribution for simple cells. However, if monocular neurons are excluded from the analysis, the argument for distinct subtypes is much less convincing. This is in contrast to the finding by Hubel and Livingstone (1987) that cells were either sharply disparity tuned or unselective for disparity; Hubel and Livingstone did not observe any borderline cases. But, as noted above, this discrepancy may reflect criteria differences.

Several observations also suggest that disparity tuning bandwidth is not uniquely related to binocular disparity processing per se and, as applied in previous experiments, cannot be used to identify distinct classes of disparity-sensitive neurons. First, in experiments by Poggio and Fischer (1977) and Poggio and Talbot (1981), only horizontal disparities were manipulated, even if the cell's preferred orientation was horizontal. Therefore, for cells with preferred orientations near horizontal, a given horizontal disparity would produce little if any disparity along the axis orthogonal to the orientation of the stimulus. Only if the cells were strongly end-stopped and the stimulus length was appropriately adjusted would the cell demonstrate any disparity sensitivity (Hubel and Wiesel 1970; Maske et al. 1986b). In fact, for a population of cells that were not end-stopped and that had identical disparity sensitivities, the disparity tuning bandwidth measured for a given neuron with the use of the paradigm of Poggio et al. would vary systematically with its preferred orientation. Therefore it is possible that the bandwidths of some cells were artificially large because their preferred orientation was not near vertical.

In the present study, the absolute bandwidth of a given cell's binocular phase tuning function varied with the cell's spatial frequency tuning characteristics (see DeAngelis et al. 1991; Freeman and Ohzawa 1986a). Cells that were selective for high spatial frequencies produced phase tuning functions that were quite narrow in absolute terms. For example, for a cell that had an optimum spatial frequency of 4 cycles/deg, a retinal image displacement of 7.5 arcmin would change the cell's response from maximum binocular facilitation to maximum binocular suppression. This value compares favorably with previous observations by both Poggio (1991) and Hubel and Livingstone (1987) that changes in disparity on the order of 6-8 arcmin produced sharp changes in the binocular response amplitude of the best "tuned excitatory" neurons. On the other hand, cells selective for low spatial frequencies showed broad disparity tuning bandwidths. For example, for a phase-specific cell that had an optimum spatial frequency of 0.4 cycles/deg, the $180^{\circ}$ phase shift required to change the cell's response from maximum binocular facilitation to the maximum suppression would be equivalent to a retinal image disparity of $1.25^{\circ}$. The critical point is that the bandwidth of the disparity tuning function of a cell is largely a product of its spatial frequency tuning characteristics (Freeman and Ohzawa 1990). For a given receptive field eccentricity, cortical cells exhibit a broad range of optimum spatial frequencies (DeValois et al. 1982). Consequently, for any given point in the visual field, one would expect to find a range of disparity tuning bandwidths. It seems reasonable that the bandwidths of the disparity tuning functions for cortical cells in the monkey, as in the cat (DeAngelis et al. 1991; LeVay and Voigt 1988), are distributed along a continuum. As a result, measures of bandwidth alone cannot be used to distinguish different functional classes of disparity-selective neurons. It is certainly not possible to predict the other functional characteristics of a cell on the basis only of a knowledge of its sensitivity to relative interocular spatial phase disparities.

In conclusion, binocular phase tuning functions are a particularly valuable measure of cortical binocular interactions. Although the degree of binocular phase selectivity does not appear to identify distinct functional classes of cortical neurons, binocular phase tuning is a robust functional property of cortical neurons. Moreover, binocular phase tuning functions reflect how the inputs from the two eyes are combined and the interocular balance between excitatory and inhibitory inputs, even when a cell is insensitive to binocular phase disparities. 
We thank H. Cheng and K. Kitagawa for help in some of the recording experiments.

This work was supported by National Institutes of Health Research Grants EY-03611, EY-08128, and RR-07146 and funds from the Greeman-Petty Professorship of the University of Houston Endowment.

Address reprint requests to E. L. Smith.

Received 22 March 1996; accepted in final form 10 March 1997.

\section{REFERENCES}

Albrecht, D. G. and Hamilton, D. B. Striate cortex of monkey and cat: contrast response function. J. Neurophysiol. 48: 217-237, 1982.

Anzai, A., Bearse, M. A., Jr., Freeman, R. D., and Cai, D. Contrast coding by cells in the cat's striate cortex: monocular vs. binocular detection. Visual Neurosci. 12: 77-93, 1995.

Barlow, H. B., Blakemore, C., and Pettigrew, J. D. The neural mechanism of binocular depth discrimination. J. Physiol. Lond. 193: 327-342, 1967.

Burkhalter, A. AND Van Essen, D. C. Processing of color, form and disparity in visual areas V2 and VP of ventral extrastriate cortex in the macaque. J. Neurosci. 6: 2327-2351, 1986.

Chino, Y. M., Smith, E. L., III, Yoshida, K., Cheng, H., AND Hamamoto, J. Binocular interactions in striate cortical neurons of cats reared with discordant visual inputs. J. Neurosci. 14: 5050-5067, 1994.

DEAN, A. F. The relationship between response amplitude and contrast for cat striate cortical neurons. J. Physiol. Lond. 318: 413-427, 1981.

DeAngelis, G. C., Ohzawa, I., And Freeman, R. D. Depth is encoded in the visual cortex by a specialized receptive field structure. Nature Lond. 352: 156-159, 1991.

DeValois, R. L., Albrecht, D. G., And Thorell, L. G. Spatial frequency selectivity of cells in macaque visual cortex. Vision Res. 22: 545-559, 1982.

Felleman, D. J. And Van Essen, D. C. Receptive field properties of neurons in area V3 of macaque monkey extrastriate cortex. J. Neurophysiol. 57: 889-920, 1987.

Ferster, D. A comparison of binocular depth mechanisms in areas 17 and 18 of the cat visual cortex. J. Physiol. Lond. 311: 623-655, 1981.

Freeman, R. D. AND OHZAWA, I. On the neurophysiological organization of binocular vision. Vision Res. 30: 1661-1676, 1990.

FreEman, R. D. AND Robson, J. G. A new approach to the study of binocular interaction in visual cortex: normal and monocularly deprived cats. Exp. Brain Res. 48: 296-300, 1982.

Hubel, D. H. and Livingstone, M. S. Segregation of form, color and stereopsis in primate area 18. J. Neurosci. 7: 3378-3415, 1987.

Hubel, D. H. And Livingstone, M. S. Color and contrast sensitivity in the lateral geniculate body and primary visual cortex of the macaque monkey. J. Neurosci. 10: 2223-2237, 1990.

Hubel, D. H. AND Wiesel, T. N. Receptive fields, binocular interaction and functional architecture in the cat's visual cortex. J. Physiol. Lond. 160: 106-154, 1962.

HubEL, D. H. AND WiEsEL, T. N. Receptive fields and functional architecture of monkey striate cortex. J. Physiol. Lond. 195: 215-243, 1968.

Hubel, D. H. AND WIESEL, T. N. Cells sensitive to binocular depth in area 18 of the macaque monkey cortex. Nature Lond. 225: 41-42, 1970.

LEOPOLD, D. A. AND LogOTHETIS, N. K. Activity changes in early visual cortex reflect monkeys' percept during binocular rivalry. Nature Lond. 379: 549-553, 1996.

LEVAY, S. AND VoIGT, T. Ocular dominance and disparity coding in cat visual cortex. Visual Neurosci. 1: 395-414, 1988.

LEVICK, W. R. AND Thibos, L. N. Analysis of orientation bias in cat retina. J. Physiol. Lond. 329: 243-261, 1982.

Livingstone, M. S. AND Hubel, D. H. Anatomy and physiology of a color system in the primate visual cortex. J. Neurosci. 4: 309-356, 1984.

LoGOTHETIS, N. AND SCHALL, J. D. Neuronal correlates of subjective visual perception. Science Wash. DC 245: 761-763, 1989.

Maske, R., Yamane, S., And Bishop, P. O. Stereoscopic mechanisms: binocular responses of the striate cells of cats to moving light and dark bars. Proc. R. Soc. Lond. B. Biol. Sci. 229: 227-256, 1986 a.

MASKe, R., YAMANE, S., AND Bishop, P. O. End-stopped cells and binocular depth discrimination in the striate cortex of cats. Proc. R. Soc. Lond. B. Biol. Sci. 229: 257-276, 1986b.

Maunsell, J.H.R. AND VAN Essen, D. C. Functional properties of neurons in middle temporal visual area of the macaque monkey. II. Binocular interactions and sensitivity to binocular disparity. J. Neurophysiol. 49: 1148-1167, 1983.

Movshon, J. A., Thompson, I. D., And Tolhurst, D. J. Spatial summation in the receptive fields of simple cells in the cat's striate cortex. J. Physiol. Lond. 283: 53-77, 1978.

Nelson, J. I., Kato, H., AND Bishop, P. O. Discrimination of orientation and position disparities by binocularly activated neurons in cat striate cortex. J. Neurophysiol. 40: 260-284, 1977.

Ni, J., Smith, E. L., III, Chino, Y. M., Kitagawa, K., and Crawford, M.L.J. Cortical binocular interactions in normal and strabismic monkeys. Soc. Neurosci. Abstr. 16: 984, 1990.

Nikara, T., Bishop, P. O., AND Pettigrew, J. D. Analysis of retinal correspondence by studying receptive fields of binocular single units in cat striate cortex. Exp. Brain Res. 6: 353-372, 1968.

OHZAWA, I. AND FREEMAN, R. D. The binocular organization of simple cells in the cat's visual cortex. J. Neurophysiol. 56: 221-242, 1986a.

Ohzawa, I. AND Freeman, R. D. The binocular organization of complex cells in the cat's visual cortex. J. Neurophysiol. 56: 243-259, 1986 b.

ORBAN, G. A. Quantitative electrophysiology of visual cortical neurons. In: Vision and Visual Dysfunction, The Neural Basis of Visual Function, edited by A. G. Leventhal. Boston, MA: CRC, 1991, vol. 4, p. 173-222.

PogGio, G. F. Processing of stereoscopic information in monkey visual cortex. In: Dynamic Aspects of Neocortical Function, edited by G. M. Edelman, W. E. Gall, and W. M. Cowan. New York: Wiley, 1984, p. 613-635.

PoGgio, G. F. Physiological basis of stereoscopic vision. In: Vision and Visual Dysfunction. Binocular Vision, edited by D. Regan. Boston, MA: CRC, 1991, p. 224-238.

Poggio, G. F. AND Fischer, B. Binocular interaction and depth sensitivity in striate and prestriate cortex of behaving rhesus monkey. J. Neurophysiol. 40: 1392-1405, 1977.

Poggio, G. F., Gonzalez, F., and Drause, F. Stereoscopic mechanisms in monkey visual cortex: binocular correlation and disparity selectivity. J. Neurosci. 8: 4531-4550, 1988.

Poggio, G. F., Motter, B. C., Squatrito, S., And Trotter, Y. Responses of neurons in visual cortex (V1 and V2) of the alert macaque to dynamic random-dot stereograms. Vision Res. 25: 397-406, 1985.

Poggio, G. F. AND TALBOT, W. H. Mechanisms of static and dynamic stereopsis in foveal cortex of the rhesus monkey. J. Physiol. Lond. 315: 469492, 1981.

Roy, J.-P., Komatsu, H., AND WuRTZ, R. H. Disparity sensitivity of neurons in monkey extrastriate area MST. J. Neurosci. 12: 478-492, 1992.

Sclar, G. and Freeman, R. D. Orientation selectivity in the cat's striate cortex is invariant with stimulus contrast. Exp. Brain Res. 46: 457-461, 1982.

SengPeil, F., BlaKemore, C., AND HARRAD, R. Interocular suppression in the primary visual cortex: a possible neural basis for binocular rivalry. Vision Res. 35: 179-195, 1995.

Skottun, B. C., DeValois, R. L., Grosf, D. H., Movshon, J. A., AlBRECHT, D. G., AND BoNDS, A. B. Classifying simple and complex cells on the basis of response modulation. Vision Res. 31: 1079-1086, 1991.

Smith, E. L., III, Chino, Y. M., Cheng, H., Hamamoto, J., and CrawFORD, M. L. J. Cortical binocular interactions in monkeys with anisometropic amblyopia (Abstract). Invest. Ophthalmol. Visual Sci. 33, Suppl.: 869, 1992a.

Smith, E. L., III, Chino, Y., Ni, J., And Cheng, H. Binocular combination of contrast signals by striate cortical neurons in the monkey. J. Neurophysiol. 78: 366-382, 1997.

SMith, E. L., III, Chino, Y. M., Ni, J., AND ChENG, H. Binocular combination of contrast signals in the striate cortex of macaque monkeys. Soc. Neurosci. Abstr. 18: 296, 1992b.

Smith, E. L., III, Chino, Y. M., Ridder, W. H., III, Kitagawa, K., AND LANGSTON, A. Orientation bias of neurons in the lateral geniculate nucleus of macaque monkeys. Visual Neurosci. 5: 525-545, 1990.

Tolhurst, D. J., Movshon, J. A., And Thompson, I. D. The dependence of response amplitude and variance of cat visual cortical neurons on stimulus contrast. Exp. Brain Res. 41: 414-419, 1981.

VARELA, F. J. AND Singer, W. Neuronal dynamics in the visual corticothalamic pathway revealed through binocular rivalry. Exp. Brain Res. 66: $10-20,1987$

WoLfe, J. M. Stereopsis and binocular rivalry. Psychol. Rev. 93: 269-282, 1986.

WONG-RILEY, M.T.T. Changes in the visual system of monocularly sutured or enucleated cats demonstrable with cytochrome oxidase histochemistry. Brain Res. 171: 11-28, 1979. 